\title{
əVertical Modes and Effective Stability of Quasi-2-Day Waves
}

\author{
YUKARI SUMI \\ Graduate School of Science, The University of Tokyo, Tokyo, Japan \\ HiROHIKO MASUNAGA \\ Institute for Space-Earth Environmental Research, Nagoya University, Nagoya, Japan
}

(Manuscript received 12 April 2019, in final form 17 April 2019)

\begin{abstract}
A quasi-2-day wave is known as a convectively coupled westward inertia-gravity (WIG) wave with a shallower equivalent depth (or slower phase speed) than the dry counterpart. This study investigates the relationship between the phase speed of quasi-2-day waves and effective static stability in terms of a vertical mode perspective. By using WIG filters with different equivalent depths, different phases of the 2-day wave are identified by filtering brightness temperature data obtained from geostationary satellites. The composite time series and the vertical modes in the tropical atmosphere are calculated from reanalysis data. The largescale dynamical fields of the composite WIG waves are explained by the superposition of the first four baroclinic modes. Phase speed of the moist vertical mode is computed by applying the Radon transform to the mode transform coefficient. Different vertical modes share a common phase speed, which is slower than its dry counterpart, implying that the wave is not dispersive. To address the question of what slows the vertical modes, the effective static stability is evaluated by defining the degree of cancellation between diabatic heating and adiabatic cooling due to the ascent. This cancellation is confirmed to be almost complete for the first baroclinic mode as expected theoretically. The effective static stability is found to be higher for a higher vertical mode, but this change over different vertical modes is not as rapid as predicted from nondispersiveness. Possible reasons for this disagreement are discussed herein.
\end{abstract}

\section{Introduction}

A quasi-2-day wave is a synoptic-scale disturbance in the tropical atmosphere that is accompanied by organized cloud clusters propagating westward with a period of about 2 days (Takayabu 1994a,b; Takayabu et al. 1996; Chen and Houze 1997; Haertel and Johnson 1998; Haertel and Kiladis 2004; Haertel et al. 2008). Characteristics of the 2-day waves have been well analyzed using sounding observations in Tropical Ocean and Global Atmosphere Coupled Ocean-Atmosphere Response Experiment (TOGA COARE) intensive observation period (IOP). The COARE 2-day waves propagate at a phase speed of about $10-30 \mathrm{~m} \mathrm{~s}^{-1}$ and have a zonal wavelength of about 1000-4000 km (e.g., Takayabu et al. 1996; Haertel and Johnson 1998).

๑ Denotes content that is immediately available upon publication as open access.

Corresponding author: Yukari Sumi, sumi@eps.s.u-tokyo.ac.jp
The 2-day wave is the most fundamental element of the hierarchy of the convectively coupled equatorial waves (CCEWs) and is often observed in the active phase of the Madden-Julian oscillation (MJO) (Nakazawa 1988; Clayson et al. 2002). It is widely recognized that the dynamics of the 2-day wave are explained by $n=1$ convectively coupled westward inertia-gravity (WIG) wave (Takayabu 1994b; Takayabu et al. 1996; Haertel and Johnson 1998; Wheeler and Kiladis 1999; Wheeler et al. 2000; Haertel and Kiladis 2004; Haertel et al. 2008; Kiladis et al. 2009; Tulich and Kiladis 2012). The dry equatorial waves, not coupled with convection, are derived from the shallow-water equation linearized in equatorial beta plane (Matsuno 1966). Meanwhile, because of coupling with moist convection, dynamical characteristics of CCEWs are not fully explained by the linear theory.

The activity of CCEWs has been extensively investigated by computing a space-time spectrum of tropical convection including cloudiness, precipitation, and water vapor (Takayabu 1994a; Wheeler and Kiladis 1999; 
Wheeler et al. 2000; Roundy and Frank 2004; Kiladis et al. 2009; Yasunaga and Mapes 2012; and many others). In a wavenumber-frequency diagram, spectral peaks of CCEWs lie along the theoretical dispersion curves with an equivalent depth of about $12-50 \mathrm{~m}$. This is consistent with the fact that CCEWs have a slower phase speed (or shallower equivalent depth) than their dry counterparts.

A variety of convection-wave coupling mechanisms have been proposed to explain the reduction in the phase speed (for reviews, see Straub and Kiladis 2003; Kiladis et al. 2009). One of the well-established ideas, which emphasizes the prominent role of the first baroclinic mode (or deep convective mode), explains the suppressed phase speed in terms of the reduced static stability (Neelin and Held 1987; Neelin and Yu 1994; Emanuel et al. 1994; Tian and Ramanathan 2003; Sobel and Bretherton 2003; Frierson et al. 2004; Raymond et al. 2009). It is hypothesized that adiabatic cooling due to strong upward motion is partially canceled out by diabatic heating due to latent heat release, which reduces effective static stability in a convective atmosphere. In this approach, a relatively slow phase speed of CCEWs is explained by a slowdown of the dry first mode $\left(\sim 50 \mathrm{~m} \mathrm{~s}^{-1}\right)$ due to a reduction of the effective static stability. The reduced static stability can be linked to the gross moist stability (GMS) that was originally introduced by Neelin and Held (1987), in which the square of the phase speed is proportional to GMS (Neelin and Yu 1994; Emanuel et al. 1994; Tian and Ramanathan 2003; Frierson et al. 2004) or the normalized GMS (Sobel and Bretherton 2003; Raymond et al. 2009). Another school of theory proposes the stratiform instability mechanism (Mapes 2000; Majda and Shefter 2001; Majda et al. 2004; Khouider and Majda 2006a; Kuang $2008 \mathrm{~b}$ ), which focuses on the role of the second baroclinic mode (or the stratiform mode) as a key ingredient of instability. The lower-tropospheric cooling due to the second mode decreases convective inhibition (CIN), and then drives new convection, causing CCEWs to propagate at a phase speed similar to that of the dry second mode $\left(\sim 25 \mathrm{~m} \mathrm{~s}^{-1}\right)$. It should be noted that the reduced static stability mechanism does not necessarily contradict the stratiform instability mechanism: a slowdown of the first mode may be caused by a reduction of static stability, whereas the second mode could concurrently play an independent role. However, the role of the second mode is not yet fully understood. One possible explanation is that shallow circulation due to the second mode can moisten the middle troposphere, which may trigger the subsequent deep convection (and hence, the first mode) (Kuang 2008b; Peters and Bretherton 2006; Haertel et al. 2008). Another possible explanation is that the second mode is only a response to the first mode (Frierson 2007; Raymond and Fuchs 2007).

The multimode structure of CCEWs first appeared in the stratiform instability mechanism proposed by Mapes (2000). Subsequently, many theoretical and observational studies have demonstrated that dynamical structures of CCEWs can be captured by a superposition of a few vertical modes and have extensively explored the concept of the possible coordination between the first and the higher vertical modes (Majda and Shefter 2001; Straub and Kiladis 2003; Haertel and Kiladis 2004; Majda et al. 2004; Peters and Bretherton 2006; Khouider and Majda 2006a; Tulich et al. 2007; Tulich and Mapes 2008; Haertel et al. 2008; Kuang 2008a; Kiladis et al. 2009; Tulich and Kiladis 2012). In multimode models, phase speed is not likely to significantly disagree among different vertical modes, because otherwise the wave would necessarily be heavily dispersive and would not propagate over a long distance. This is the crux of the issue with the artificial nature of vertical mode thinking. In the real atmosphere, it is not necessarily clear why different vertical modes can have a common slow phase speed constituting a coherent wave packet without being immediately dispersed. More observational analysis is needed to better understand the multimode structure of CCEWs and the slowdown of the vertical modes, and this is still worthwhile studying. For this purpose, we carry out a vertical mode decomposition of 2-day waves by using satellite and reanalysis data, and explore the slowness and nondispersiveness of the vertical modes.

The change in phase speed of CCEWs is affected not only by convective coupling but also by environmental fields where the wave is embedded (Wheeler et al. 2000; Straub and Kiladis 2002; Yang et al. 2003, 2007a; Roundy 2008; Dias and Pauluis 2009; Kiladis et al. 2009; Dias and Pauluis 2011; Dias and Kiladis 2014; Yasunaga and Mapes 2014). In addition, the phase speed, structure, and coupling mechanism can vary during the wave life cycle. From this perspective, recent studies have focused on the different phases of the wave by using a subdivision approach (Yasunaga and Mapes 2014; Blanco et al. 2016). Motivated by these studies, we investigate the multimode structure of the slow and fast phases of the 2-day wave by applying the vertical mode decomposition to their composite profiles separately. The slow and fast components (or phases) are detected by WIG filters with different equivalent depth as described in section $2 \mathrm{a}$.

This paper consists of the following sections. In section 2, the data and methods are described. In section 3 , we perform vertical mode transform of 2-day waves. In section 4, we discuss the potential factors impacting the slowdown mechanism of vertical modes. Section 5 summarizes the present findings. 


\section{Data and methods}

\section{a. Data}

This study analyzes 10 years (2000-09) of satellite and reanalysis data. The analysis area is the whole tropical region between $10^{\circ} \mathrm{N}$ and $10^{\circ} \mathrm{S}$. All satellite data are projected onto a $0.25^{\circ}$ grid.

Infrared (IR) brightness temperature (TBB) data are used to identify convective peaks of quasi-2-day waves (see section $2 \mathrm{~b}$ ). TBB data are obtained from the globalmerged IR brightness temperature data (mergedIR), version 6, by Janowiak et al. (2001). MergedIR is a highresolution gridded global dataset derived from the merging of the Geostationary Operational Environmental Satellite (GOES)-8/10, Meteorological Satellite (Meteosat)-7/5, and Geostationary Meteorological Satellite data. The spatial coverage is between $60^{\circ} \mathrm{N}$ and $60^{\circ} \mathrm{S}$. The horizontal resolution is about $0.0364^{\circ}$, and the temporal resolution is $30 \mathrm{~min}$. Owing to the high temporal resolution of mergedIR, we were able to construct a composite time series with a time increment of $30 \mathrm{~min}$ (see section $2 \mathrm{c}$ for more details).

The precipitation data in the tropical ocean area are obtained from the Tropical Rainfall Measuring Mission (TRMM) data product. The TRMM satellite was launched in November 1997 and ended in April 2015. It is a sun-asynchronous satellite orbiting with an inclination angle of about $35^{\circ}$ and carrying a Precipitation Radar (PR), which estimates the vertical profile of precipitation. The horizontal and vertical resolutions of TRMM PR are about $4 \mathrm{~km}$ and $250 \mathrm{~m}$, respectively. The near-surface precipitation data in PR2A25 level 2, version 6 (Iguchi et al. 2000), are used to analyze the variance in precipitation of 2-day waves.

To analyze the environmental fields associated with the 2-day waves, we use the European Centre for MediumRange Weather Forecasts (ECMWF) interim reanalysis (ERA-Interim) data (Simmons et al. 2007). The horizontal resolution is $1.5^{\circ}$, and the temporal resolution is $6 \mathrm{~h}$. The total number of pressure levels is 38 , in which pressure intervals are not uniform. The ERA-Interim variables utilized in this work are the geopotential height $\phi$, temperature $T$, specific humidity $q$, zonal wind velocity $u$, meridional wind velocity $v$, and pressure velocity $\omega$. The analysis area covers the whole oceanic tropical region between $10^{\circ} \mathrm{N}$ and $10^{\circ} \mathrm{S}$ as selected using the ERA-Interim sea-land flag.

\section{b. Filtering analysis}

A space-time filtering of TBB is performed to identify a convective peak of 2-day wave. Here we assume that a convectively coupled WIG wave is a practical indicator of the 2-day wave. The procedure used in the present study is similar to that of Sumi and Masunaga (2016) and is briefly summarized below.

The filtering is performed for every 2-yr period from 2000 to 2009 (i.e., 2000-01, 2002-03, .. , 2008-09) because a large memory space is required for fast Fourier transform (FFT). First, TBB is averaged over the meridional band between $10^{\circ} \mathrm{N}$ and $10^{\circ} \mathrm{S}$, and then a longitude-time cross section of the averaged TBB is constructed. Missing data are filled in by linear interpolations over time. The mean and the linear components in time, identified by least squares fit at each longitude, are then removed (e.g., Masunaga et al. 2006). Second, the FFT is applied to the time series of anomalous TBB by using a split cosine bell tapering function to avoid spectral leakage. Third, a WIG filter (the filter design is described below) is applied to a wavenumber-frequency domain to isolate individual WIG waves. Fourth, the filtered TBB is transformed back to the longitude-time domain. Finally, the peaks of the WIG waves are defined as local minima of the filtered TBB lower than -2 standard deviations (SDs). This threshold is used to prevent the composite wave structures from being contaminated by irrelevant background convective signals.

Figure 1 shows the power spectrum of TBB normalized by red noise background spectrum. The background spectrum is computed by repeated smoothing of the raw spectrum with a 1-2-1 filter (Wheeler and Kiladis 1999; Kiladis et al. 2009; and many others). As reported in previous studies, the spectral peak of WIG wave is located between the dispersion curves with an equivalent depth of about $15-45 \mathrm{~m}$. It is more linear than predicted from theoretical dispersion curves of WIG wave, but is still dispersive, unlike the Kelvin wave.

The WIG filter is defined as a wavenumber-frequency domain including the zonal wavenumber $k=1-14$ and the equivalent depth $h_{e}=12-50 \mathrm{~m}$. The filter is rather larger than WIG filters with $h_{e}=17-50 \mathrm{~m}$ used in previous studies (e.g., Wheeler and Kiladis 1999). However, this difference does not seriously affect our conclusions. To isolate different phases of WIG wave, the WIG filtering is performed for each subfilter with different equivalent depths (e.g., Yasunaga and Mapes 2014). The faster and slower components of the wave are identified by the subfilters with the higher and shallower equivalent depth, respectively. The subfilters are denoted by h15/5, h25/15, h35/25, h45/35, and h55/45 in the order of increasing equivalent depths (black boxes in Fig. 1). For instance, the $\mathrm{h} 15 / 5$ filter includes the equivalent depths from 15 to $5 \mathrm{~m}$. The wavenumber in the range $k=1-14$ is applied equally to all the subfilters. 


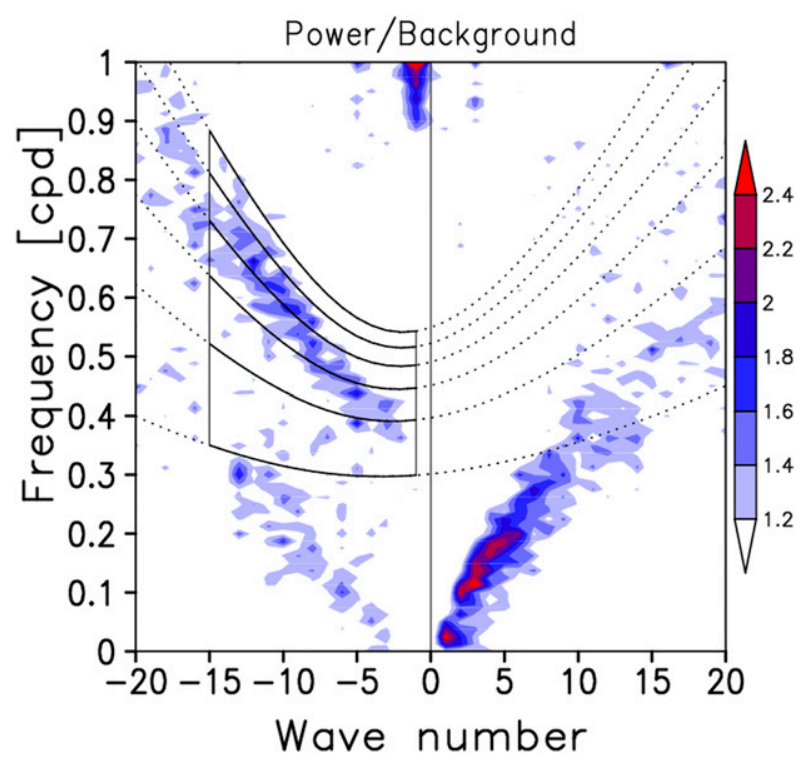

FIG. 1. The raw power spectrum normalized by the background spectrum in wavenumber-frequency (cpd) domain. A negative and positive wavenumber mean westward and eastward mode, respectively. The shading begins at a value of 1.2 , which is significant at the $95 \%$ level with 182 degree of freedom in a chisquared test. Dotted lines represent dispersion curves of $n=1$ WIG wave with equivalent depth of $5,15,25,35,45$, and $55 \mathrm{~m}$. Five subfilters are indicated by black boxes.

The spectral peak of WIG wave spreads across the subfilter boxes, which may lead to a cross contamination between the slower and faster components. The slower components are accompanied by more convection, because the raw spectrum has more power at shallower equivalent depth, and hence the contamination of slower to faster components can be more serious. The influence of the cross contamination on our results will be discussed in section $4 \mathrm{~b}$ and appendix A.

It is noted that much of the filtered signal is filtered noise. In fact, a nonpropagating convective signal is sometimes identified as a propagating wavelike disturbance (see also Fig. A1 in appendix A). Instead of the filtering method, an object-based approach has been used to avoid a contamination of nonpropagating convective signals (e.g., Dias et al. 2012). However, in this study, the filtered noise can be averaged out in the composite fields by using a large number of the composite base points with $-2 \mathrm{SD}$ threshold (see section 2c). We will show below that dynamical features of the composite WIG waves are qualitatively consistent with those in previous studies.

\section{c. Composite analysis}

The composite base points are defined as the convective peaks of the filtered WIG waves, which are samples in the whole equatorial ocean region between $10^{\circ} \mathrm{N}$ and $10^{\circ} \mathrm{S}$ (the total sample number is 331748 ). Various satellite and reanalysis data are composited around the base points. Individual base points only provide discrete snapshots because of a coarse temporal sampling of the composited data: daily observational frequencies are four times (every $6 \mathrm{~h}$ ) and less than two times in reanalysis data and low-Earth-orbiting (LEO) satellite data, respectively. However, a statistically continuous time series is constructed by compositing a huge number of reanalysis and satellite snapshots with respect to the observational time difference between mergedIR and the composited data. The time interval of the composite time series is set to $0.5 \mathrm{~h}$, because the composite base points are detected from 0.5-hourly mergedIR data. For a more detailed description, refer to section 2e in Sumi and Masunaga (2016).

Most of the composite base points are found in the warm pool region (not shown), which is consistent with the fact that the convectively coupled WIG waves (or 2-day waves) are most prominently observed in the IndoPacific Ocean region (Wheeler and Kiladis 1999; Kiladis et al. 2009; and many others). Therefore, the composite results may be affected by background conditions of the warm pool region where the WIG waves are most active. Regional differences will be briefly described in section $3 \mathrm{~b}$.

\section{d. Radon transform}

The phase speed of CCEW is usually computed as a regression coefficient of the peaks of convective anomalies in a longitude-time domain (e.g., Wheeler et al. 2000). The Radon transform (RT) method is also used in an objective manner to calculate propagation speeds of tropical synoptic-scale disturbances (Yang et al. 2007b; Dias and Pauluis 2011; Dias et al. 2012). In the present study, the RT method is adopted to compute the phase speed of the WIG waves (section 3a) and that of the moist vertical modes (section 3c). It is noted that the estimated phase speed is insensitive to the difference between the evaluation methods (not shown).

The procedure is briefly summarized here [see the appendix in Yang et al. (2007b) for more details]. The anomalous field of longitude-time domain is projected along a line at angle $\theta$ with respect to the longitude axis. The energy of the projected data would have maximum amplitude when the projection axis is perpendicular to the ridges and troughs of the wave in the course of varying $\theta$ from $0^{\circ}$ to $180^{\circ}$. With this angle denoted by $\theta_{\perp}$, the angle perpendicular to the projection angle $\left(\theta_{\perp}+90^{\circ}\right)$ gives the wave propagation direction in the longitude-time domain. Then the phase speed is calculated as the slope of the propagation direction. 


\section{e. Vertical mode}

Vertical mode decomposition is a useful tool to analyze dynamical structure of tropical disturbances and is widely used in observational and theoretical studies of mesoscale convective systems (Mapes and Houze 1995; Mapes 1998) and CCEWs (Haertel and Johnson 1998; Haertel and Kiladis 2004; Khouider and Majda 2006b; Tulich et al. 2007; Tulich and Mapes 2008; Haertel et al. 2008; Kuang 2008a; Tulich and Mapes 2010; Tulich and Kiladis 2012). There are a number of ways to calculate vertical normal modes in the atmosphere (e.g., Kasahara and Puri 1981; Silva Dias et al. 1983; Fulton and Schubert 1985). We adopt the method proposed by Fulton and Schubert (1985), in which the vertical modes are derived from the primitive-equation system in the pressure coordinate. The vertical mode is obtained by solving a discrete eigenvalue equation:

$$
-\partial_{p} \frac{p}{\bar{S} R} \partial_{p} \psi_{n}(p)=c_{n}^{2} \psi_{n}(p),
$$

where $R$ is the gas constant of dry air, $\bar{S}=R \bar{T} / p c_{p}-\partial_{p} \bar{T}$ is the static stability of the basic state (the overbar denotes temporal and area averages), and $c_{p}$ is the dry air heat capacity at constant pressure $), \psi_{n}(p)$ is a normalized structure function of the $n$th dry vertical mode, and $c_{n}$ is the phase speed. Note that $\psi_{n}(p)$ consists of a normalized orthogonal system and only depends on pressure.

Dynamical profile $A(x, y, p, t)$ is projected onto each vertical mode component $A_{n}(x, y, p, t)$ :

$$
A_{n}(x, y, p, t)=\hat{A}_{n}(x, y, t) \psi_{n}(p) .
$$

The $A(x, y, p, t)$ represents $u, v, \phi$, and $D$, where $D=\partial_{p}(Q / S)$ is forced divergence and $Q$ is heating rate. The mode coefficient $\hat{A}_{n}(x, y, t)$ is obtained by

$$
\hat{A}_{n}=\left\langle\psi_{n} \mid A\right\rangle=\frac{1}{p_{b}-p_{t}} \int_{p_{t}}^{p_{b}} \psi_{n} A d p
$$

where the bracket $\langle A \mid B\rangle$ represents the vertical inner product for functions $A$ and $B$ of pressure, and $p_{t}$ and $p_{b}$ are the pressure values at the top and bottom boundaries, respectively. Here, $\psi_{n}(p)$ satisfies $\left\langle\psi_{n} \mid \psi_{m}\right\rangle=\delta_{m n}$, where $\delta_{m n}$ is the Kronecker delta. The mode components $T_{n}, \omega_{n}$, and $Q_{n}$ are calculated by substituting $\psi_{n}$ in the thermodynamic equation, continuity equation, and definition of $D$, respectively [see Eq. (12) or Eq. (13)].

Equation (1) is solved by assuming a rigid lid at $p_{t}$, where $p_{t}=100 \mathrm{hPa}$ and $p_{b}=1000 \mathrm{hPa}$. The pressure coordinate between $p_{t}$ and $p_{b}$ is divided into 36 layers with a uniform thickness of $25 \mathrm{hPa}$. Then the total number of vertical modes is $36(n=0-35)$. ERA-Interim data in the pressure coordinate (between $p_{t}$ and $p_{b}$ ) are also vertically

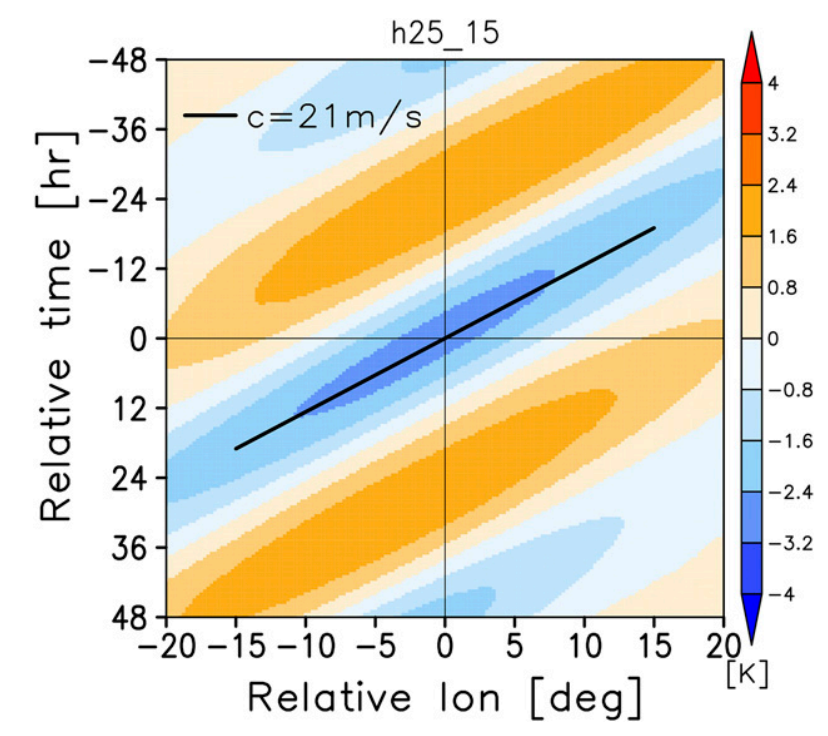

FIG. 2. Longitude-time diagram of anomalous TBB (K) for a WIG wave identified with the h25/15 filter. The slope of the black line represents a phase speed of about $21 \mathrm{~m} \mathrm{~s}^{-1}$.

interpolated, with uniform spacing $(25 \mathrm{hPa})$, by cubic spline interpolation. It is noted that the vertical wavelength of the vertical mode varies with $\bar{S}$, especially near the tropopause layer where $\bar{S}$ increases rapidly. The $\bar{T}$ is calculated as a temporal-domain-averaged temperature between $10^{\circ} \mathrm{N}$ and $10^{\circ} \mathrm{S}$ over a $10-\mathrm{yr}$ period (2000-09) because regional/seasonal differences in temperature profile are small between $p_{b}$ and $p_{t}$ (not shown).

The phase speeds of vertical modes, obtained as eigenvalues of Eq. (1), are faster in the lower mode. The phase speeds $\left(c_{1}=52, c_{2}=27, c_{3}=20, c_{4}=15 \mathrm{~m} \mathrm{~s}^{-1}\right)$ and the equivalent depths $\left(H_{n}=c_{n}^{2} / g: H_{1}=274, H_{2}=75\right.$, $\left.H_{3}=39, H_{4}=23 \mathrm{~m}\right)$ of the first four vertical modes are overall consistent with those calculated in previous studies. For example, Tulich and Kiladis (2012), using ERA-Interim data, showed that the phase speeds of the first four vertical modes are 51, 22, 18, and $14 \mathrm{~m} \mathrm{~s}^{-1}$. Haertel et al. (2008), using TOGA COARE data, showed that the phase speeds of the first three vertical modes are 52,26 , and $19 \mathrm{~m} \mathrm{~s}^{-1}$. In addition, the pressure levels of the peaks and nodes of each vertical mode are roughly consistent with those in the previous studies (not shown).

\section{Results}

\section{a. Phase speed of composite WIG waves}

Figure 2 shows a longitude-time diagram of anomalous TBB composited around the WIG peaks identified by the h25/15 filter. A convectively active area with a negative TBB anomaly propagates westward over a period of about two days. The phase speed of the 


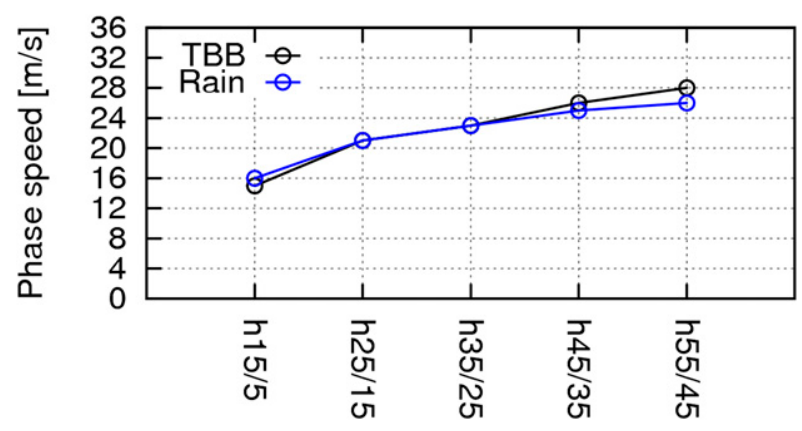

FIG. 3. Phase speed of a composite WIG wave. Black and blue circles represent the phase speeds estimated by RT of anomalous $\mathrm{TBB}$ and anomalous precipitation, respectively.

composite WIG wave is computed by applying the RT method to the composite TBB and precipitation anomalies (see section $2 \mathrm{~d}$ for more detail). In Fig. 2, a slope of the black line represents the phase speed of $21 \mathrm{~m} \mathrm{~s}^{-1}$. The composite precipitation is rather noisy because of a coarse temporal sampling of TRMM satellite (not shown), but this has little effect on the estimation of the phase speed.

Figure 3 shows the phase speed for slower and faster components of WIG waves. As expected, a subfilter with a deeper (shallower) equivalent depth results in a faster (slower) component. It is shown that the range of the estimated phase speed $\left(15-28 \mathrm{~m} \mathrm{~s}^{-1}\right)$ is consistent with that in previous studies $\left(10-30 \mathrm{~m} \mathrm{~s}^{-1}\right)$. The phase speeds of TBB agree well with that of precipitation, indicating that the estimated phase speeds are insensitive to parameter choice (cloud or precipitation). These results support the robustness of the RT method for use in the present application.

\section{b. Vertical mode transform}

To understand the gross features of WIG waves, the dynamical profiles are projected onto each vertical mode. The vertical mode decomposition has been performed for the simulated and observed 2-day waves. It is demonstrated that the tilted dynamical structure of the 2-day wave can be captured by the first two vertical modes (Haertel and Kiladis 2004; Kuang 2008a). Additional higher modes (i.e., the third and fourth modes) are also considered in other studies (Haertel et al. 2008; Tulich and Mapes 2008; Tulich and Kiladis 2012). In the present study, a similar vertical mode decomposition is applied to the composite WIG waves.

Figure 4 shows a time-pressure cross section of the mode transform component $\omega_{n}$ for the first four baroclinic modes, where $\omega_{n}$ is calculated by substituting $\psi_{n}$ in the continuity equation [see Eq. (12)]. A strong
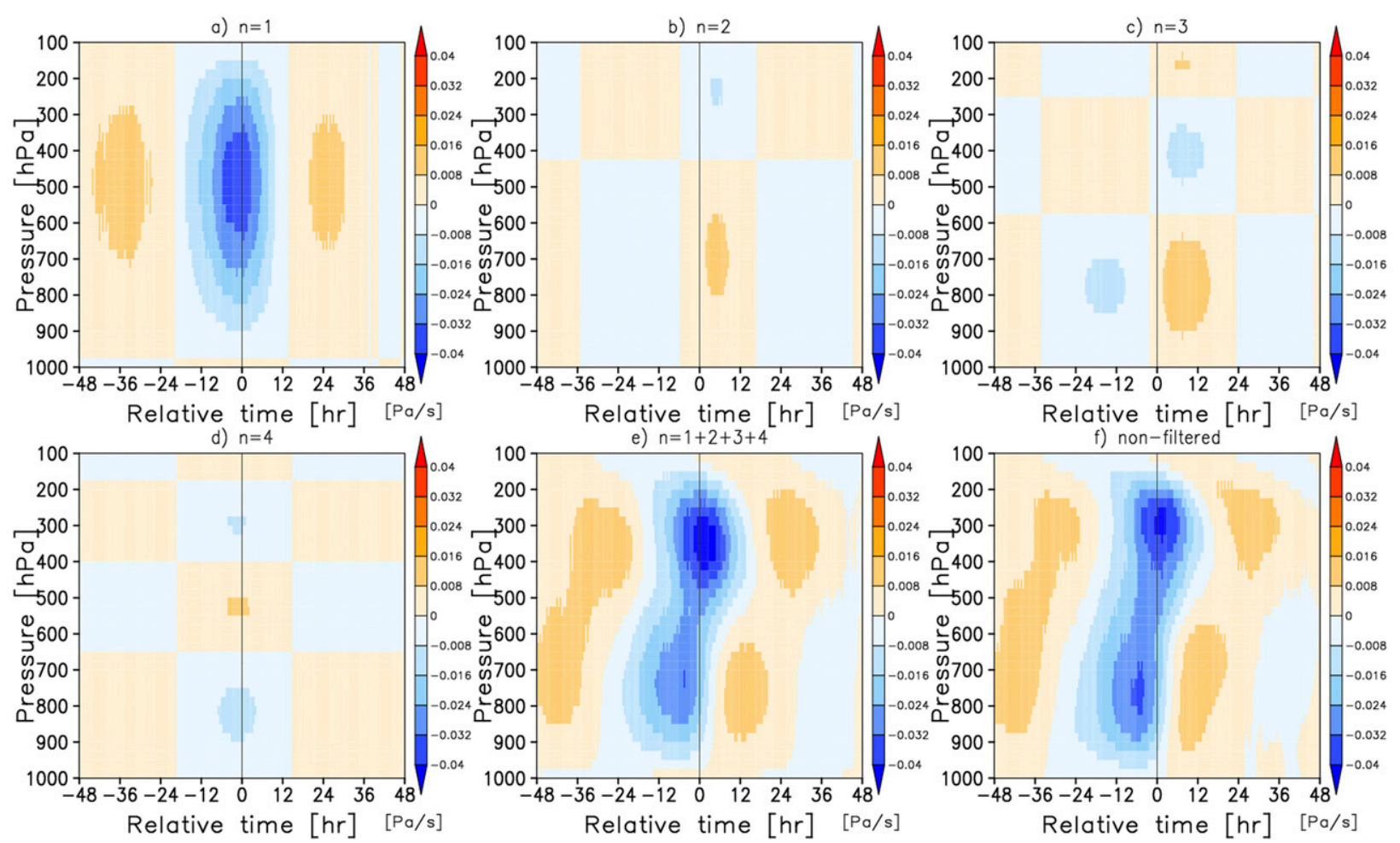

FIG. 4. Time-pressure cross section of pressure velocity $\left(\mathrm{Pa} \mathrm{s}^{-1}\right.$ ) of WIG wave identified with the h25/15 filter: (a) $\omega_{1}$, (b) $\omega_{2}$, (c) $\omega_{3}$, (d) $\omega_{4}$, (e) a superposition of $\omega_{n}$ from $n=1$ to $n=4$, and (f) composite $\omega$. Negative and positive values denote upward and downward motion, respectively. 

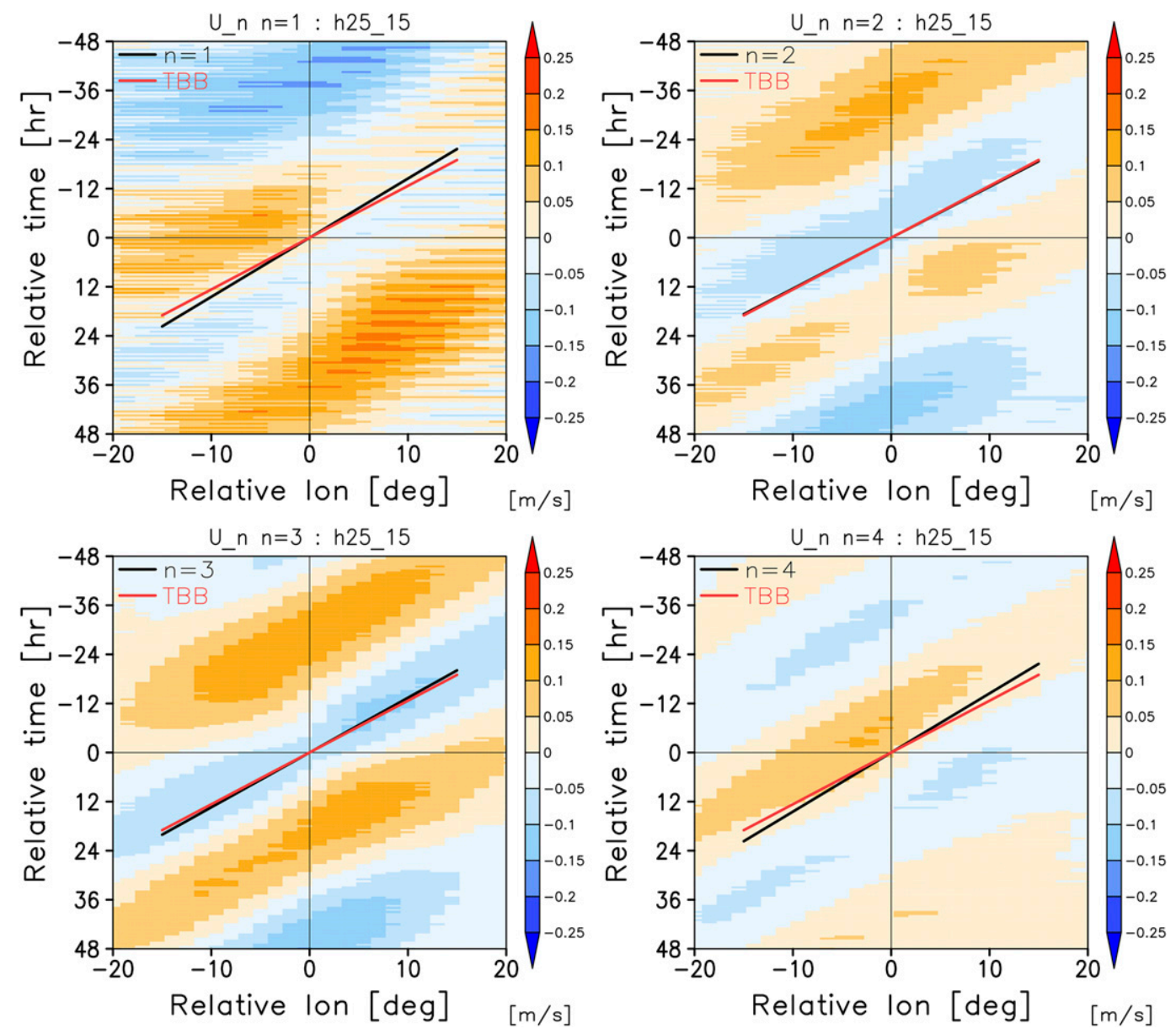

FIG. 5. Longitude-time diagram of mode transform coefficient of zonal wind $\hat{u}_{n}$ (the first four modes) for a WIG wave identified with the h25/15 filter. Shades of red and blue represent westerly and easterly zonal wind anomalies at the surface, respectively. The slope of the black line corresponds to the phase speed of vertical mode, which is estimated by RT of $\hat{u}_{n}$. The red line is the same as black line in Fig. 2.

updraft with a single-sign structure due to the first mode develops around $0 \mathrm{~h}$ (Fig. 4a). It reaches a maximum of about $500 \mathrm{hPa}$ in the middle troposphere at $-3 \mathrm{~h}$. Although the first mode has the largest amplitude among the first four modes, the higher modes are not negligible to explain the wave dynamics. The second and third modes exhibit a dipole-like structure with opposite signs in the lower and upper half of the troposphere (Figs. 4b,c). These two modes are almost in phase with each other and have peaks around $\sim+6 \mathrm{~h}$, which is roughly quadrature with the first mode. The time lag between the first mode and the second and third modes is estimated to be about $10 \mathrm{~h}$. The negative peak of the third mode in the lower troposphere represents a shallow updraft preceding deep convection. Such dipole-like structures preceding and lagging the first mode are consistent with the congestus mode and the stratiform mode, respectively.
The fourth mode is almost in phase with the first mode (Fig. 4d), which may provide a modest modulation to the first mode.

A vertically tilted and top-heavy $\omega$ profile is captured by a superposition of the first four vertical modes (Fig. 4e), which is qualitatively consistent with the observed one (Fig. 4f). Also, other dynamical profiles of the wave $(u, v, D, \phi$, and $Q)$ are sufficiently explained by the first four modes (not shown). Additional higher vertical modes $(n>4)$ are needed to reproduce a boomerang-like temperature structure, as reported in previous studies (Haertel and Kiladis 2004; Haertel et al. 2008; Kuang 2008a; Tulich and Kiladis 2012). Results for the other subfilters are similar (not shown).

The tilting $\omega$ profile (Fig. 4f) is common in different ocean regions but is modified by background conditions (not shown). For example, the maximum level of 


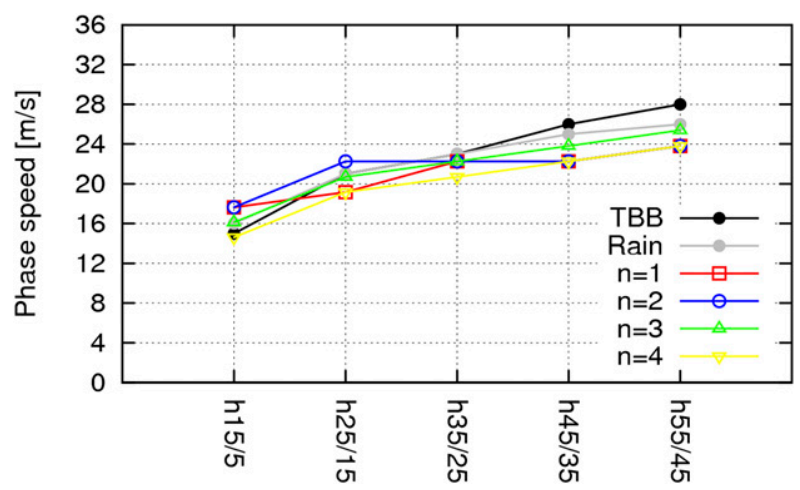

FIG. 6. Phase speed of the moist vertical mode estimated by RT of $\hat{u}_{n}$ for $n=1$ (red), $n=2$ (blue), $n=3$ (green), and $n=4$ (yellow). The phase speeds estimated form TBB (black) and precipitation (gray) are as in Fig. 3.

convection is slightly lower in the eastern Pacific than in the warm pool region, which is explained by the regional difference of the large-scale atmospheric circulation (e.g., Back and Bretherton 2006). It is worth performing vertical mode transform of the composite WIG waves in different regions, and this will be addressed in future work.

\section{c. Phase speed of the vertical mode}

The phase speed of the moist vertical mode is computed by applying the RT method to the mode transform coefficient $\hat{A}_{n}(x, y, t)$. Figure 5 shows a longitude-time diagram of the coefficient $\hat{u}_{n}$. In the first and fourth modes (the second and third modes), the surface wind converges (diverges) around the composite center, which corresponds to the upward (downward) motion in Fig. 4.

Figure 6 shows the phase speeds of the moist vertical mode estimated from $\hat{u}_{n}$. Phase speed of the moist vertical mode is slower than the dry contour part and is roughly equal to that of the composite WIG wave estimated from TBB and precipitation anomalies. It should be noted that $u_{n}$ itself is not filtered but is simply composited against the filtered TBB peaks, so the agreement in the phase speed is not by design. The phase speed of the dry first mode is, in theory, a few times faster than that of the higher modes (see section 2e), whereas different moist modes have a similar phase speed between themselves in Fig. 6. This nondispersive nature of the moist vertical modes is also verified for other dynamical parameters, such as geopotential, horizontal wind divergence, and heating rate (not shown).

\section{d. Definition of $\alpha_{n}$}

In previous studies, a relatively slow phase speed of the 2-day wave has been examined in terms of the effective static stability. Haertel and Kiladis (2004), using a

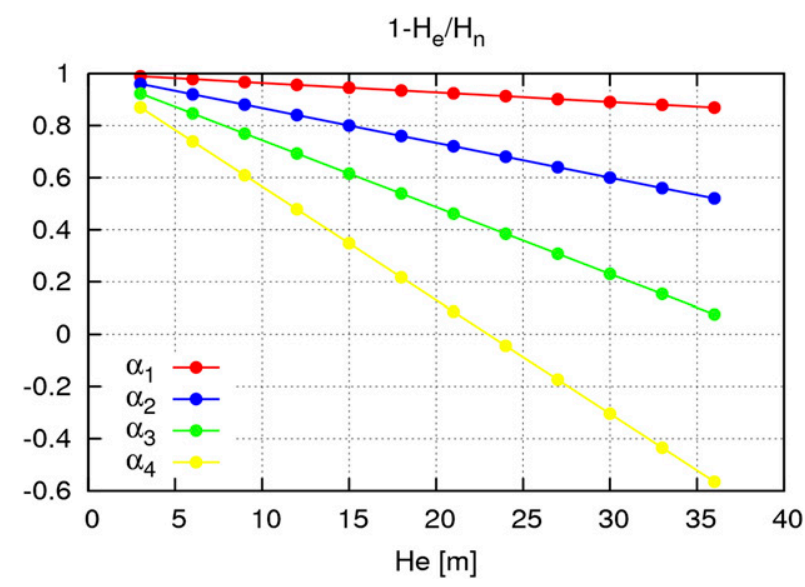

FIG. 7. Plot of $H_{e}$ vs $\tilde{\alpha}_{n}\left(=1-H_{e} / H_{n}\right)$ for the first four modes, where $H_{e}$ is changed from 3 to $36 \mathrm{~m}$ with an interval of $3 \mathrm{~m}$.

linear primitive-equation model, showed that a degree of reduction of the equivalent depth of the first two vertical modes is equal to that of static stability. Haertel et al. (2008) showed that for COARE 2-day wave, a degree of reduction in static stability is larger in the lower vertical mode. Following these studies, we derive a diagnostic equation to examine the slowdown of the vertical modes.

First, the relationship between static stability $S$ and effective static stability $S_{e}$ is considered. For a fixed vertical mode, the thermodynamic equation is written as follows:

$$
\partial_{t} T_{n}=S \omega_{n}+Q_{n},
$$

where $S \omega_{n}$ and $Q_{n}$ represent, respectively, adiabatic heating (cooling) due to descent (ascent) and diabatic source including latent and radiative heating terms. Assume that $Q_{n}$ is expressed as

$$
Q_{n} \sim-\alpha_{n} S \omega_{n},
$$

where $\alpha_{n}$ is a positive constant representing the degree of cancellation between adiabatic heating (cooling) and diabatic cooling (heating) (Neelin and Held 1987; Haertel and Kiladis 2004; Haertel et al. 2008; Kiladis et al. 2009). Substituting Eq. (5) into Eq. (4) yields

$$
\partial_{t} T_{n} \sim S_{e} \omega_{n},
$$

where $S_{e}$ is defined as

$$
S_{e}=\left(1-\alpha_{n}\right) S .
$$

It is assumed that $0<\alpha_{n}<1$ since $S_{e}$ is considered to be positive. When $\alpha_{n}$ is large, $S_{e}$ is small, and thus, a degree of reduction of static stability is large.

Second, the relationship between static stability and equivalent depth of the vertical mode is considered. 

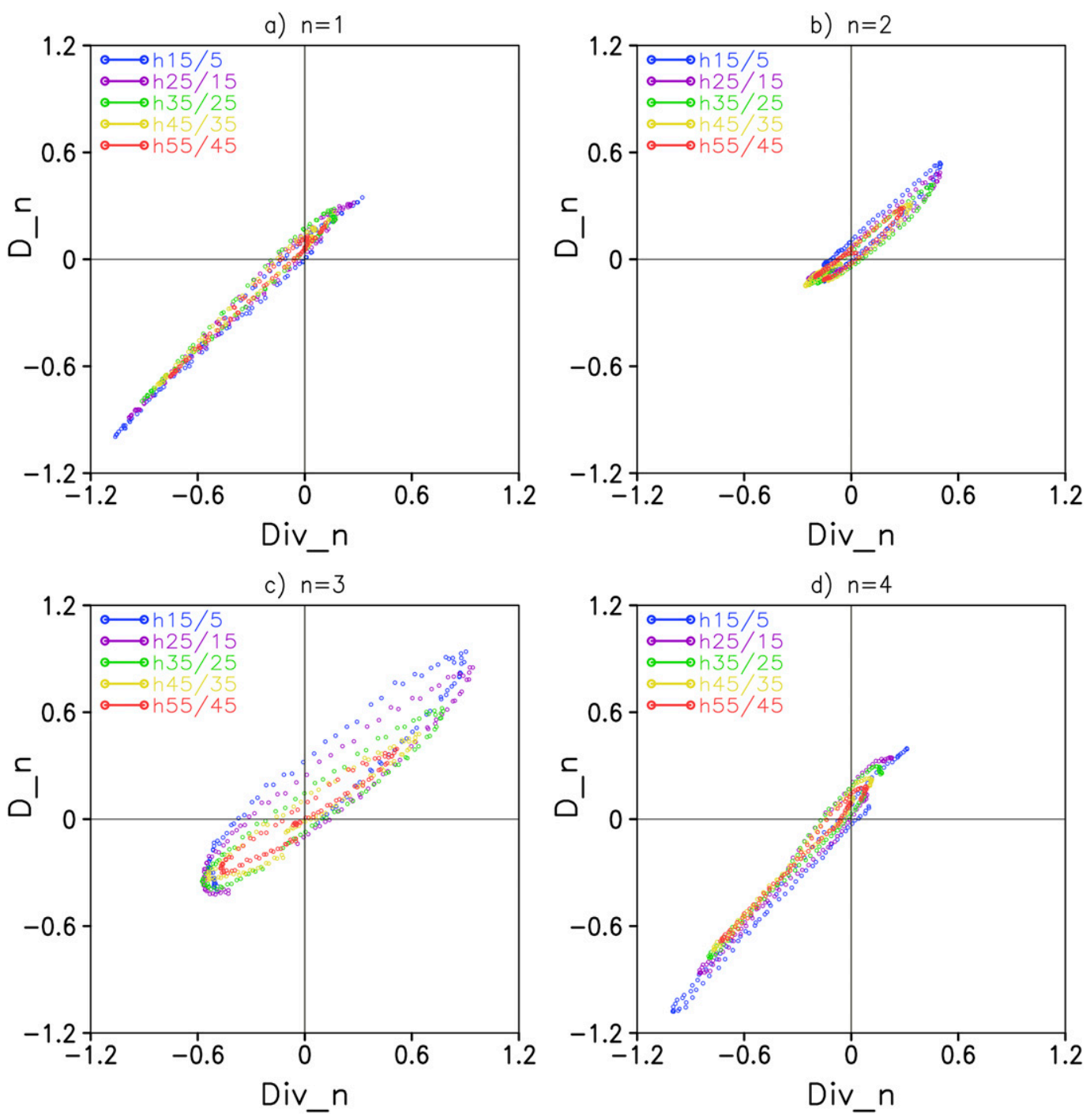

FIG. 8. Scatterplot of the mode transform coefficients $\nabla \cdot \hat{V}_{n}$ and $\hat{D}_{n}$ between -24 and $+24 \mathrm{~h}$ for the first four modes. The coefficients are in units of $10^{-6} \mathrm{~s}^{-1}$. Different colors represent different phase speeds of WIG wave.

Here, the equivalent depth of the dry vertical mode and that of the moist vertical mode are denoted by $H_{n}$ and $H_{n}^{\text {moist }}$, respectively. In a shallow-water system, $H_{n}$ is written as

$$
H_{n}=\frac{N^{2}}{g\left(m_{z, n}^{2}+\frac{1}{4 h^{2}}\right)},
$$

where $N$ is a constant Brunt-Väisälä frequency, $g$ is the gravitational acceleration, $h$ is the scale height, and $m_{z, n}$ is the vertical wavenumber (e.g., Lindzen 1967; Wheeler et al. 2000). As $H_{n}$ is a function of $m_{z, n}$ and $S\left(\propto N^{2}\right)$, it is proportional to $S$ for a fixed vertical mode with constant $m_{z, n}$. Assuming that $H_{n}^{\text {moist }}$ is also proportional to $S_{e}$, we obtain

$$
\frac{H_{n}^{\text {moist }}}{H_{n}} \sim \frac{S_{e}}{S}
$$

Equation (9) indicates that a degree of reduction of equivalent depth (i.e., $H_{n}^{\text {moist }} / H_{n}$ ) is related to that of static stability (i.e., $S_{e} / S$ ). It should be noted that $H_{n}$ and $H_{n}^{\text {moist }}$ cannot be exactly expressed in a simple form as shown in Eq. (8), because static stability is a function of height in the real atmosphere. This issue, however, is neglected here because the changes in the static stability profile are small except near the surface and tropopause.

Figure 6 suggested that moist vertical modes have a common equivalent depth $H_{e}\left(\sim H_{1}^{\text {moist }} \sim H_{2}^{\text {moist }} \sim\right.$ $\left.H_{3}^{\text {moist }} \sim H_{4}^{\text {moist }}\right)$ because they have a similar phase speed 
among themselves. Then replacing $H_{n}^{\text {moist }}$ with $H_{e}$ in Eq. (9) yields

$$
\frac{H_{e}}{H_{n}} \sim \frac{S_{e}}{S} .
$$

Combining Eqs. (7) and (10), we finally obtain a diagnostic equation for $\alpha_{n}$ :

$$
\alpha_{n} \sim \tilde{\alpha}_{n}=1-\frac{H_{e}}{H_{n}}
$$

where $\tilde{\alpha}_{n}=1-H_{e} / H_{n}$ is a monotonically decreasing function of $H_{e}$ with an increment of $-1 / H_{n}$. The value of $\tilde{\alpha}_{n}$ changes more steeply with respect to $H_{e}$ in the higher mode (Fig. 7).

Equation (11) suggests that a slowdown of the vertical mode $\left(H_{e} / H_{n}<1\right)$ can be explained by a reduction of effective static stability that each mode feels $\left(1-\alpha_{n}\right)$. There are two implications of Eq. (11). First, for a given $n, \alpha_{n}$ decreases with $H_{e}$ with an increment of $-1 / H_{n}$. Second, the higher mode has a smaller $\alpha_{n}$ when different moist vertical modes have a common $H_{e}$. Therefore, it follows that for nondispersive waves, adiabatic cooling cancels diabatic heating more weakly in the higher mode. The possible application of Eq. (11) will be discussed in section 4 .

\section{e. Estimation of $\alpha_{n}$}

Now $\alpha_{n}$ is computed according to Eq. (5). The mode transform components $\omega_{n}$ and $Q_{n}$ are written as

$$
\begin{aligned}
& \omega_{n}=-\nabla \cdot \hat{V}_{n} \int_{p_{t}}^{p} \psi_{n} d p, \\
& Q_{n}=\hat{D}_{n} S \int_{p_{t}}^{p} \psi_{n} d p,
\end{aligned}
$$

where $\nabla \cdot \hat{V}_{n}$ and $\hat{D}_{n}$ are the mode transform coefficients of horizontal wind divergence $\nabla \cdot V_{n}$ and forced divergence $D$, respectively. Following Yanai et al. (1973), the term $Q$ is computed as the apparent heat source by using ERA-Interim data. Substituting Eqs. (12) and (13) into Eq. (5) gives

$$
\begin{aligned}
\alpha_{n} & =-\frac{Q_{n}}{S \omega_{n}} \\
& =\frac{\hat{D}_{n}}{\nabla \cdot \hat{V}_{n}} .
\end{aligned}
$$

Therefore, $\alpha_{n}$ is calculated as the least squares coefficient between $\hat{D}_{n}$ and $\nabla \cdot \hat{V}_{n}$. In Haertel and Kiladis (2004), $\alpha_{n}$ is computed as a ratio of $Q_{n}$ to $S \omega_{n}$ at a

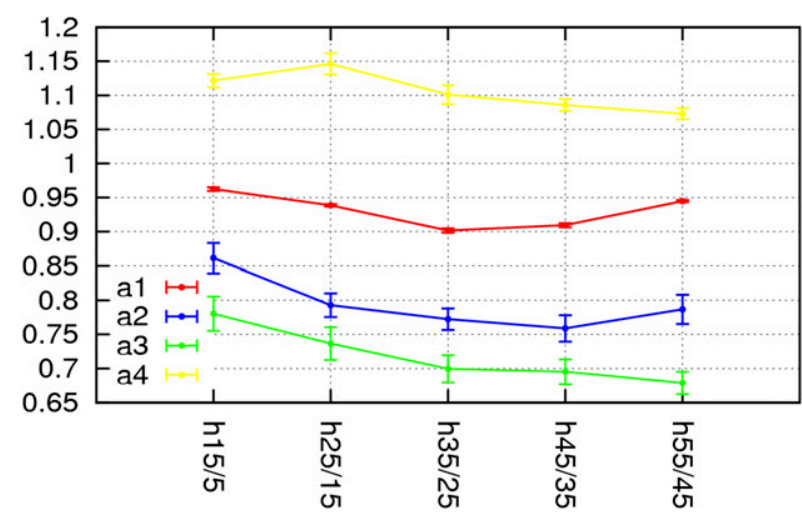

FIG. 9. Plot of $\alpha_{n}$ calculated as a least squares coefficient between $\nabla \cdot \hat{V}_{n}$ and $\hat{D}_{n}$ (see Fig. 8). The vertical axis starts at 0.65 . Error bars indicate the $95 \%$ confidence intervals. Different color denotes different modes $(n=1-4)$.

pressure level of the maximum variances. Their method is different from ours, as mentioned above, but $\alpha_{n}$ is insensitive to the difference in the estimation methods. They showed $\alpha_{1}=0.95$ and $\alpha_{2}=0.75$ for the simulated 2-day wave with a phase speed of $16 \mathrm{~m} \mathrm{~s}^{-1}$, which is roughly consistent with our result shown below: $\alpha_{1}=0.96, \alpha_{2}=0.85$, and $\alpha_{3}=0.75$ for the WIG wave component with a phase speed of $15 \mathrm{~m} \mathrm{~s}^{-1}$ (see Fig. 9).

Figure 8 shows a scatterplot of $\nabla \cdot \hat{V}_{n}$ versus $\hat{D}_{n}$ for the first four vertical modes. Amplitudes of $\nabla \cdot \hat{V}_{n}$ and $\hat{D}_{n}$ are larger (smaller) in shallower (higher) equivalent depth, because the slower (faster) components are accompanied with more (less) convection. The first and fourth modes are tightly distributed around a linear line (Figs. 8a,d), while the second and third modes are more scattered (Figs. 8b,c). Then it is implied that $\alpha_{n}$ (and therefore, $S_{e}$ ) is time independent for the first and fourth modes, but is more time dependent for the second and third modes. This seems to be consistent with the concept of GMS: the vertical component of GMS is separated into a time-independent part due to the first mode and a time-dependent part due to the second mode (e.g., Inoue and Back 2015).

In Fig. 9, the estimated values of $\alpha_{n}$ are positive and smaller than 1 as predicted by Eq. (7), except in the fourth mode. The following results are noted: 1) Values of $\alpha_{n}$ are smaller in the higher mode $\left(\alpha_{1}>\alpha_{2}>\alpha_{3}\right)$, supporting that different moist vertical modes have a common $H_{e}$ (or phase speed). 2) Slower (faster) components of WIG wave, accompanied by more (less) convection, have a larger (smaller) $\alpha_{n}$. This result would be consistent with previous studies suggesting that the cancellation between diabatic heating and adiabatic cooling is large (small) in convective active (inactive) regions (e.g., Haertel et al. 2015; Powell 2017). 3) For a 

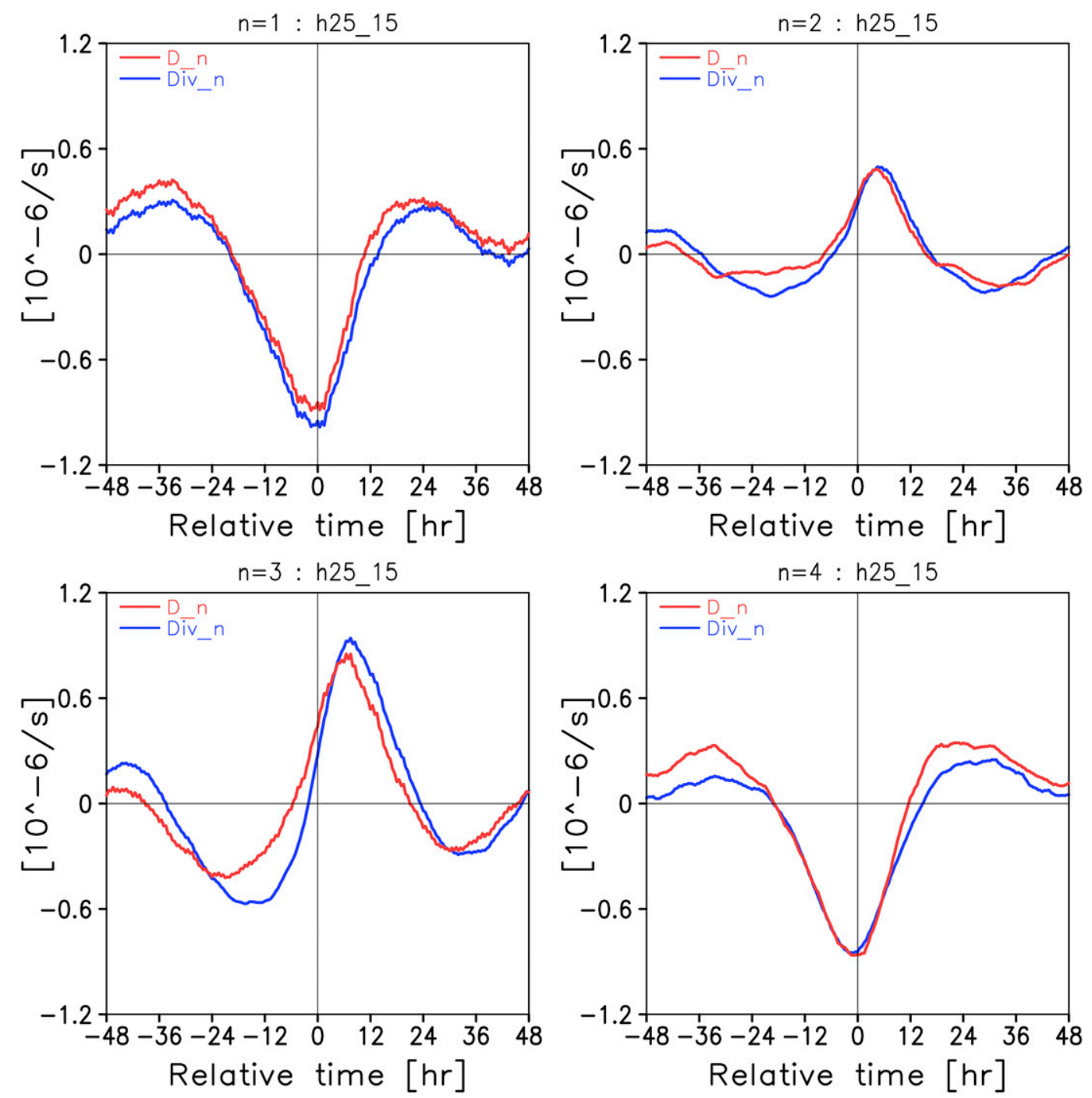

FIG. 10. Time series of the mode transform coefficients $\nabla \cdot \hat{V}_{n}$ (red) and $\hat{D}_{n}$ (blue) for a WIG wave identified with the filter h25/15. The coefficients are in units of $10^{-6} \mathrm{~s}^{-1}$.

given vertical mode, $\alpha_{n}$ appears not to decrease with $H_{e}$ as sharply as expected theoretically (cf. Fig. 7). The decreasing trend of $\alpha_{n}$ is statistically significant in the slower components, because the overlap of the error bars is small enough, especially for the first mode. A relatively large overlap of error bars in the faster component indicates that the cross contamination between the slower and faster components would occur. The slight decrease trend of $\alpha_{n}$ will be further discussed in section 4.

Figure 10 shows a time series of $\hat{D}_{n}$ and $\nabla \cdot \hat{V}_{n}$ for the first four vertical modes. Temporal variation of the fourth (third) mode is quite similar to that of the first (second) mode (see also Fig. 8). It is suggested that a superposition of the first and fourth modes (the second and third modes) may correspond to a so-called deep convective mode (stratiform and congestus modes). For the first and fourth modes, $\nabla \cdot \hat{V}_{n}$ is almost in phase with $D_{n}$. This in-phase relationship seems to be consistent with the reduced stability model, in which diabatic heating is rapidly canceled by adiabatic cooling because of the ascending motion in order to maintain convective quasi equilibrium (e.g., Emanuel et al. 1994). On the other hand, $\nabla \cdot \hat{V}_{n}$ lags slightly behind $\hat{D}_{n}$ for the second and third modes, leading to a partial cancellation of the diabatic heating. Results for the other subfilters are similar (not shown).

In Fig. 10, $\hat{D}_{4}$ has a slightly larger amplitude than $\nabla \cdot \hat{V}_{4}$, which results in $\alpha_{4}>1$ (Fig. 9). It is predicted from Eq. (7) that $\alpha_{n}>1$ can lead to $S_{e}<0$ (or $H_{e}<0$ ). However, we consider a situation in which $S_{e}$ cannot be negative because $0<\alpha_{n}<1$ (and thus, $S_{e}>0$ ) is 


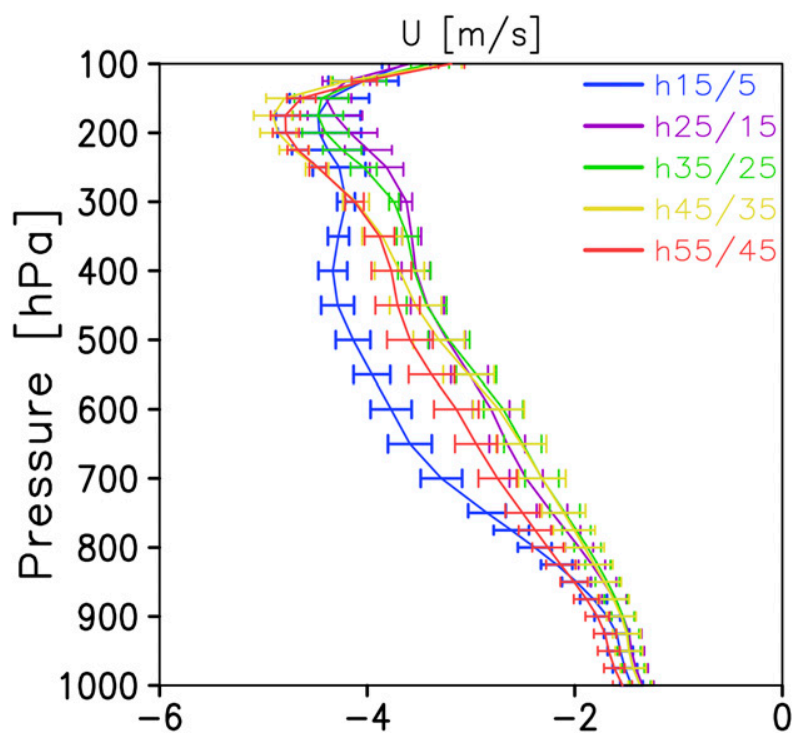

FIG. 11. Vertical profile of mean zonal wind $\bar{u}\left(\mathrm{~m} \mathrm{~s}^{-1}\right)$, which is defined as a time mean $( \pm 48 \mathrm{~h})$ of the composite zonal wind at a composite center. Different colors represent different phase speeds of the WIG wave. Error bars denote the standard deviation of $\bar{u}$.

assumed in deriving Eq. (11). Therefore, the fourth mode with a negative $S_{e}$ is excluded in the following discussion of Eq. (11). We do not necessarily deny the possibility that effective static stability can be negative (e.g., Raymond 2001; Fuchs and Raymond 2007), but this is beyond the scope of the present study.

\section{Discussion}

A diagnostic equation for $\alpha_{n}$ [Eq. (11)] is derived following the reduced stability mechanism, indicating that a slowdown of the vertical mode is approximately described by a reduction of static stability. However, Fig. 9 shows that $\alpha_{n}$ does not decrease as sharply as predicted by Eq. (11). To validate the equation, the equivalent depth of WIG waves is computed in section $4 \mathrm{a}$, and then $\alpha_{n}$ is compared with $\tilde{\alpha}_{n}$ in section $4 \mathrm{~b}$.

\section{a. Estimation of $H_{e}$}

The equivalent depth of CCEWs is estimated from the Doppler-shifted dispersion curve on a space-time diagram. Observational and theoretical studies show that equatorial waves are affected not only by the Doppler shifting due to an ambient zonal flow but also by non-Doppler effects (e.g., Zhang and Webster 1989; Yang et al. 2003, 2007a; Stechmann and Majda 2009). In Takayabu (1994b), the equivalent depth of WIG waves, observed during December-February in the Southern Hemisphere, is estimated to be about $20 \mathrm{~m}$, when considering the Doppler shift of the mean westerly flow
TABLE 1. Phase speed and mean zonal flow for each WIG wave identified with different WIG filters. Standard deviations of the mean zonal flows calculated from the sample number of 192 are shown in parentheses. Units are $\mathrm{m} \mathrm{s}^{-1}$.

\begin{tabular}{lcccc}
\hline \hline Filter & $c$ & $U_{850}$ & $U_{\text {ave }}$ & $U_{200}$ \\
\hline $\mathrm{h} 15 / 5$ & 15 & $2.0(0.14)$ & $3.2(0.10)$ & $4.5(0.40)$ \\
$\mathrm{h} 25 / 15$ & 21 & $1.7(0.12)$ & $2.8(0.10)$ & $4.2(0.26)$ \\
$\mathrm{h} 35 / 25$ & 23 & $1.7(0.11)$ & $2.6(0.10)$ & $4.4(0.22)$ \\
$\mathrm{h} 45 / 35$ & 26 & $1.7(0.16)$ & $2.9(0.17)$ & $4.9(0.17)$ \\
$\mathrm{h} 55 / 45$ & 28 & $2.0(0.13)$ & $3.2(0.14)$ & $4.8(0.13)$ \\
\hline
\end{tabular}

at $850 \mathrm{hPa}$. Dias and Kiladis (2014) shows that the equivalent depth of CCEWs is similar across seasons and basins. In addition, they estimate the equivalent depth of WIG waves to be about $25 \mathrm{~m}$ by considering the Doppler shift of the mean barotropic flow. In the present study, a similar estimation of equivalent depth is carried out as described below.

To assess the Doppler shift, we choose three mean zonal flows at different pressure levels: $\bar{u}$ at $850 \mathrm{hPa}$ $U_{850}, \bar{u}$ at $200 \mathrm{hPa} U_{200}$, and the pressure-averaged $\bar{u}$ from 850 to $200 \mathrm{hPa} U_{\text {ave }}$. The mean zonal wind $\bar{u}$ is defined as the time mean $( \pm 48 \mathrm{~h})$ of composite zonal wind at the composite center. It is easterly in the whole troposphere and is insensitive to the difference in the wave speed (Fig. 11). This result suggests that the waves are sampled from a relatively uniform background condition, regardless of their propagation characteristics. There is no significant correlation between the mean zonal flow and the phase speed of WIG waves (Table 1), which is consistent with Yasunaga and Mapes (2014). It is considered that the amount of Doppler shifting is small because the mean flow is sufficiently slower than the intrinsic wave speed.

The values of the wavenumber $k$, the frequency $f$, and $H_{e}(U)$ are summarized in Table $2 ; H_{e}\left(U_{0}\right)$ represents $H_{e}$ estimated by considering no Doppler effect $(\bar{u}=0)$. The values in Table 2 are computed as follows: In the case of the filter h25/15, a zonal extent of negative TBB anomaly is about $18^{\circ}$ (see Fig. 2), leading to $\lambda \sim 2 \times 18^{\circ}\left(\sim 36 \times 10^{5} \mathrm{~m}\right)$ and $k \sim 10$. Considering Doppler shift due to $U_{850}=1.7 \mathrm{~m} \mathrm{~s}^{-1}$, intrinsic frequency is calculated as $f\left(U_{850}\right)=\left(c-U_{850}\right) / \lambda \sim 0.46 \mathrm{cpd}$. Substituting the values of $k$ and $f\left(U_{850}\right)$ into dispersion curve of $n=1$ WIG wave, $H_{e}\left(U_{850}\right)$ is estimated to be $17.2 \mathrm{~m}$. As predicted theoretically, $H_{e}(U)$ and $f(U)$ are smaller (larger) in the strong easterly (westerly) wind.

b. $\alpha_{n}$ versus $\tilde{\alpha}_{n}$

Here, we test the application of the diagnostic equation for $\alpha_{n}$ [Eq. (11)]. Figure 12 shows $\alpha_{n}$ and $\tilde{\alpha}_{n}(U)$ for the first three vertical modes, where $\tilde{\alpha}_{n}(U)=1-H_{e}(U) / H_{n}$ is computed from $H_{e}(U)$ in Table 2 . It is found that $\alpha_{n}$ 
TABLE 2. Phase speed $c\left(\mathrm{~m} \mathrm{~s}^{-1}\right)$, zonal wavenumber $k$, frequency $f(\mathrm{cpd})$, and equivalent depth $H_{e}(\mathrm{~m})$.

\begin{tabular}{lcrcccccccc}
\hline \hline Filter & $c$ & $K$ & $f\left(U_{0}\right)$ & $f\left(U_{850}\right)$ & $f\left(U_{\text {ave }}\right)$ & $f\left(U_{200}\right)$ & $H_{e}\left(U_{0}\right)$ & $H_{e}\left(U_{850}\right)$ & $H_{e}\left(U_{\text {ave }}\right)$ & $H_{e}\left(U_{200}\right)$ \\
\hline h15/5 & 15 & 13.89 & 0.50 & 0.43 & 0.39 & 0.54 & 14.8 & 10.0 & 7.60 \\
h25/15 & 21 & 9.92 & 0.50 & 0.46 & 0.43 & 0.40 & 22.0 & 17.2 & 14.2 \\
h35/25 & 23 & 10.35 & 0.57 & 0.53 & 0.51 & 0.46 & 31.0 & 24.8 & 22.0 \\
h45/35 & 26 & 10.12 & 0.63 & 0.59 & 0.56 & 0.51 & 42.2 & 34.8 & 30.2 \\
h55/45 & 28 & 10.20 & 0.69 & 0.64 & 0.61 & 0.57 & 52.2 & 42.6 & 27.4 & 23.2 \\
\hline
\end{tabular}

best matches with $\tilde{\alpha}_{n}\left(U_{850}\right)$ in the slower components, especially for the first mode. The values of $\alpha_{1}$ and $\tilde{\alpha}_{1}\left(U_{850}\right)$ are almost the same between the $\mathrm{h} 15 / 5$ and h35/25 filters. A decreasing rate of $\alpha_{1}$ is nearly equal to that of $\tilde{\alpha}_{1}\left(U_{850}\right)\left(=-1 / H_{1}\right)$. The values of $\alpha_{2}$ and $\tilde{\alpha}_{2}\left(U_{850}\right)$ are similar between the h15/5 and h25/15 filters, while a decreasing rate of $\alpha_{2}$ is more modest than that of $\tilde{\alpha}_{2}\left(U_{850}\right)\left(=-1 / H_{2}\right)$. The $\alpha_{3}$ is roughly equal to $\tilde{\alpha}_{3}\left(U_{850}\right)$ only for the h15/5 filter. A decreasing rate of $\alpha_{3}$ is different from that of $\tilde{\alpha}_{3}\left(=-1 / H_{3}\right)$. There are some possible explanations for the disagreement between $\alpha_{n}$ and $\tilde{\alpha}_{n}$ :

1) The value of $\alpha_{n}$ would depend on the accuracy of the data used in the analysis. A slight decrease trend of $\alpha_{n}$ (Figs. 9 and 12) and $\alpha_{4}>1$ (Fig. 9) would partially result from the uncertainties in ERA-Interim data because of the cumulus parameterization in a data assimilation system. In fact, Kim and Alexander (2013) shows that a rapid variation associated with WIG wave cannot be resolved well in reanalysis data. This issue may lead to a relatively large overlap of error bars of $\alpha_{n}$ in the higher modes (Figs. 9 and 12). However, we verified that the ERA-Interim is more suitable for a study of WIG waves than other reanalysis data (see appendix B for more detail). In future work, our results will be compared with $\alpha_{n}$ computed from satellite or in situ data.

2) The estimation of $\alpha_{n}$ has its own uncertainties. We assume that $\alpha_{n}$ is a time-independent parameter and compute $\alpha_{n}$ as the least squares coefficient between $\hat{D}_{n}$ and $\nabla \cdot \hat{V}_{n}$. As $\hat{D}_{1}$ changes almost linearly with $\nabla \cdot \hat{V}_{1}$ (Fig. 8), it is indicated that $\alpha_{1}$ is less dependent on time as expected theoretically. On the other hand, for the second and third modes, $\hat{D}_{n}$ does not vary linearly with $\nabla \cdot \hat{V}_{n}$, indicating that $\alpha_{n}$ would be more time dependent. Therefore, the estimation error of $\alpha_{n}$ can be large on the second and third modes. While a time dependency of $\alpha_{n}$ is not considered in the present study, we will address this issue in future work.

3) Difference of $\alpha_{n}$ between the slower and faster components (or the shallower and higher equivalent depths) may be smaller than expected from Eq. (11) because of cross contamination, which may lead to a slight decrease trend of $\alpha_{n}$.

4) In the literature, effective static stability has been introduced to explain a large-scale motion associated with the first mode that is tied to deep convection (e.g., Neelin and Held 1987; Yano and Emanuel 1991; Neelin and Yu 1994; Emanuel et al. 1994): the atmosphere is assumed to be in a state of precipitation to ignore the descending area with no precipitation, and then convective heating is rapidly canceled by adiabatic cooling because of ascending motion. As expected theoretically, $\alpha_{1}$ is roughly identical to $\tilde{\alpha}_{1}\left(U_{850}\right)$. Then it is implied that the reduced stability mechanism may be more suitable for explaining the slowdown of the first mode. However, it is not intuitively obvious how the reduced stability mechanism explains a slowdown of the higher modes. In fact, the result of $\alpha_{n} \neq \tilde{\alpha}_{n}$ for the second and third modes implies that the slowdown of the higher modes cannot be fully explained by the reduced stability mechanism.

5) A slight decrease trend of $\alpha_{n}$ can be interpreted in another way: $\alpha_{n}$ is constrained to be approximately constant for particular vertical modes and does not vary as predicted by Eq. (11). If this is true, the range of slowdown of the vertical modes that can be explained by the reduced static stability is limited.

In future work, similar analysis will be applied to other CCEWs and mesoscale disturbances in the tropics. This will provide insight into the multimode structure of CCEWs and is still worth studying.

\section{Summary}

The present study examines the slowdown of vertical modes associated with quasi-2-day waves by using satellite and reanalysis data. The 2-day waves are identified by filtered TBB (mergedIR), where the faster and slower components of the 2-day wave are separated by adopting WIG filters with different equivalent depths within a range from 5 to $55 \mathrm{~m}$. ERA-Interim data are composited around the convective peaks of WIG waves to analyze the large-scale fields associated with the 

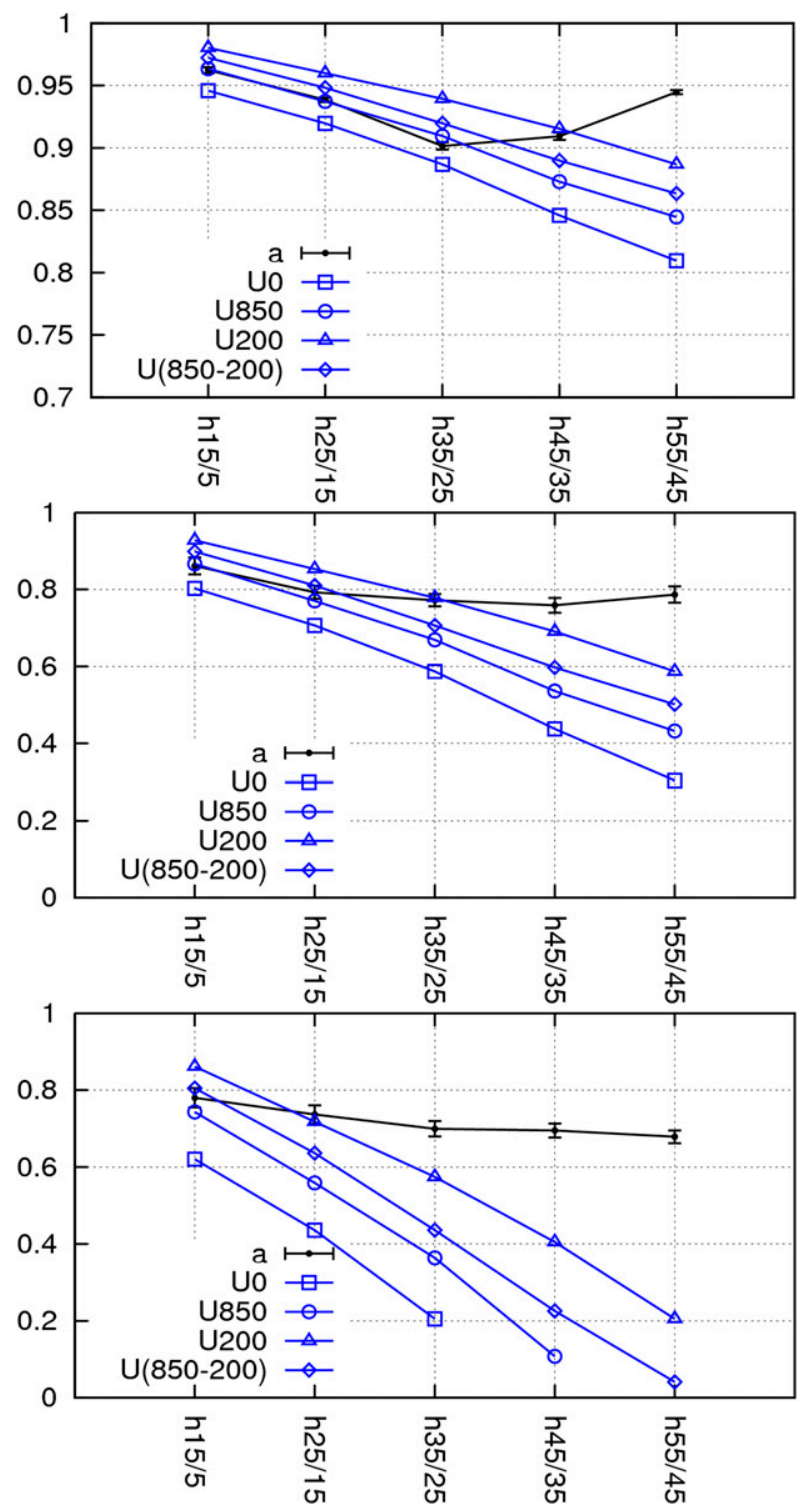

FIG. 12. Plots of $\alpha_{n}$ (black) vs $\tilde{\alpha}_{n}(U)$ (blue) for the first three modes: (top) $n=1$, (middle) $n=2$, and (bottom) $n=3$. The vertical axis starts at 0.7 in the top panel. The value of $\tilde{\alpha}_{n}(U)=1-H_{e}(U) / H_{n}$ is computed by using $H_{e}(U)$ in Table 2 . Blue squares, circles, triangles, and diamonds indicate $\tilde{\alpha}_{n}\left(\bar{u}_{0}\right), \tilde{\alpha}_{n}\left(\bar{u}_{850}\right), \tilde{\alpha}_{n}\left(\bar{u}_{200}\right)$, and $\tilde{\alpha}_{n}\left(\bar{u}_{\text {ave }}\right)$, respectively.

waves. The composite fields are further decomposed by the vertical modes calculated with the mean temperature profile (ERA-Interim) in the tropical region between $10^{\circ} \mathrm{N}$ and $10^{\circ} \mathrm{S}$.

It is shown that the dynamical structure of WIG waves are explained largely by a superposition of the first four baroclinic modes. The resulting vertically tilted, topheavy structure is consistent with the multimode structure, including the deep, congestus, and stratiform modes (e.g., Mapes 2000; Haertel et al. 2008). The phase

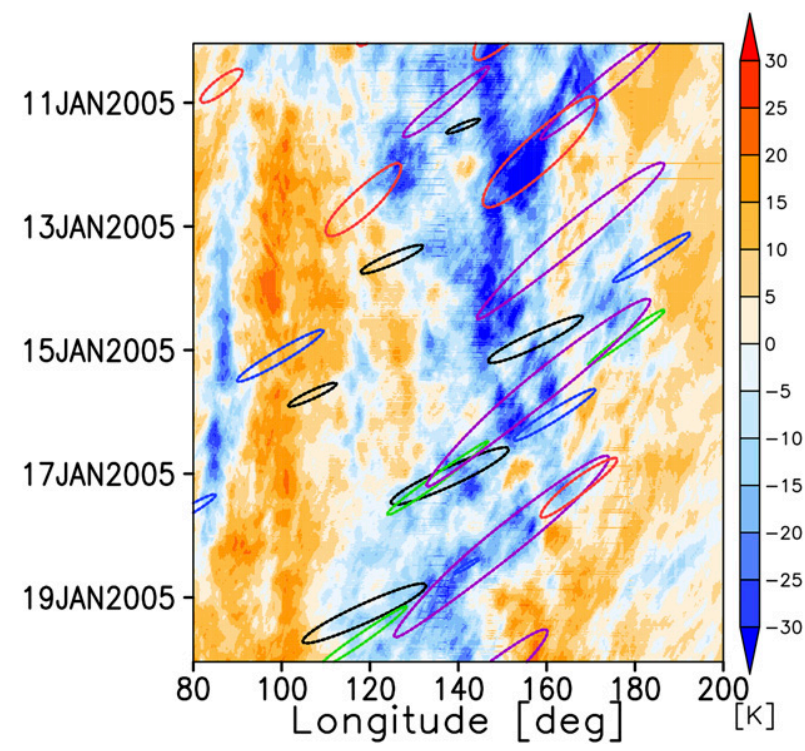

FIG. A1. Longitude-time diagram of WIG waves identified with each subfilter as well as the nonfiltered TBB anomalies from 10 to 20 January 2005 . The color shading illustrates the nonfiltered TBB anomaly. The wave envelops are indicated by contours drawn at the value of -2 standard deviations. Different colors denote different waves: h55/45 (black), h45/35 (blue), h35/25 (green), h25/15 (purple), and h15/5 (red).

speed of moist vertical modes is computed by Radon transform of the mode coefficient in the longitude-time domain. The moist vertical modes are slowed down compared to its dry counterpart, while different vertical modes have similar phase speeds, so the wave is only weakly dispersive.

In the effective stability mechanism, the slower phase speed of the first mode is attributed to the reduction of effective stability. It is not obvious, however, if the slowdown of the higher modes is also explained by a similar framework. The effective stability increases with the equivalent depth as expected from the nondispersive nature, but the rate of increase is not as steep as theoretically predicted. This disagreement is partially reconciled particularly for the first mode when the Doppler effect is taken into account, but fails to account for higher modes. The reasons include the limitation in the estimation method and physical robustness of the effective stability for the higher vertical modes. Further investigations of these outstanding issues should be addressed in future work.

Acknowledgments. The authors thank four anonymous reviewers for their helpful and constructive comments and criticisms, which greatly improved this manuscript. This work was supported by Japan Society for the Promotion of Science Grant-in-Aid for Scientific Research B (19H01966). The global-merged IR 

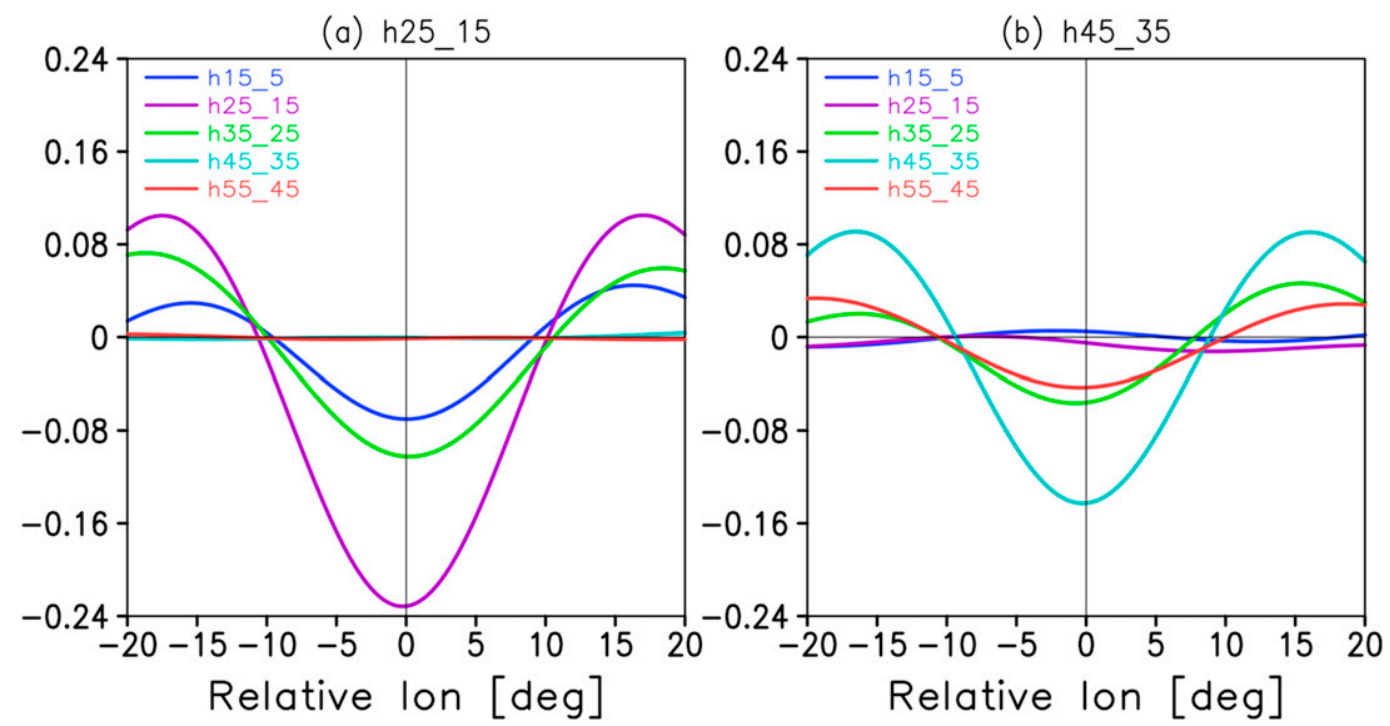

FIG. A2. Time series of the filtered TBB (K) composited around the peaks of the wave identified with the (a) h25/15 and (b) h45/35 filters.

brightness temperature data were provided by National Centers for Environmental Prediction (NCEP) Climate Prediction Center (CPC). The TRMM PR (2A25) datasets were provided by the Japan Aerospace Exploration Agency (JAXA). ERA-Interim data were provided by ECMWF. The NCEP Reanalysis data were provided by the NOAA-CIRES Climate Diagnostics Center, Boulder, Colorado. JRA-25 data were provided from the Japanese 25-year Reanalysis (JRA-25), the cooperative research project carried out by the Japan Meteorological Agency (JMA) and the Central Research Institute of Electric Power Industry (CRIEPI).

\section{APPENDIX A}

\section{Cross Contamination}

Figure A1 shows WIG wave components identified with each subfilter, as well as the nonfiltered TBB anomalies, from 10 to 20 January 2005. The slower and faster components overlap or penetrate each other in several places, implying that cross contamination may have occurred in our analysis. To assess the effect of the contamination, the filtered TBB is composited around the peak of the faster (the h25/15 filter) and slower (the h45/35 filter) components. The slower (faster) component's contamination of the faster (slower) component can be significant, if the amplitude of the slower (faster) component is large around the peak of the faster (slower) component. In Fig. A2, the amplitudes of the faster (slower) component are significantly small around the peak of the slower (faster) component.
Therefore, it is considered that the cross-contamination effect is not so serious in our results.

\section{APPENDIX B}

\section{Comparison with Other Reanalysis Datasets}

To test that ERA-Interim is suitable for our analysis, we compare apparent heat source $Q$ calculated from

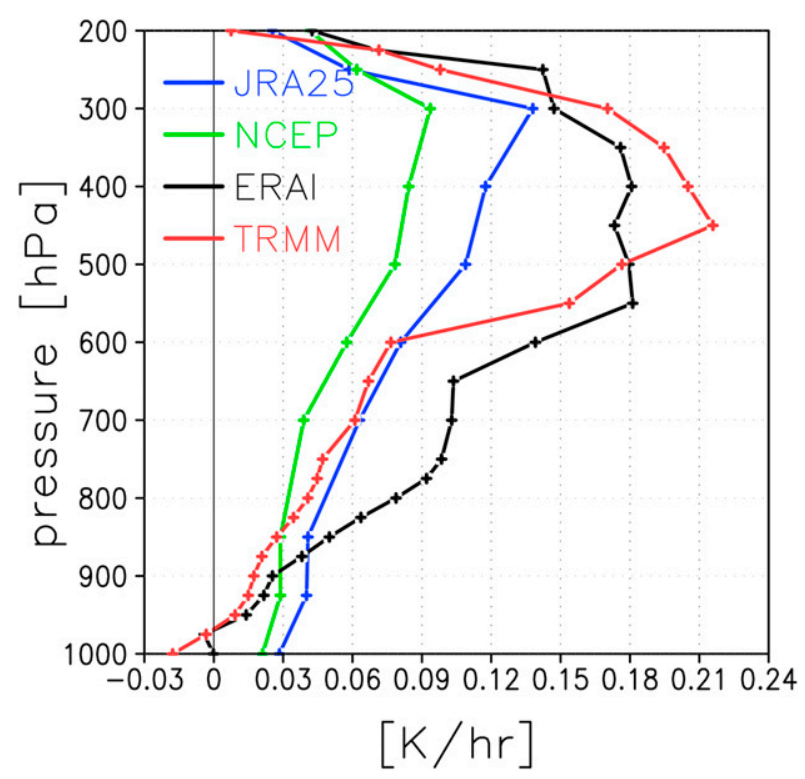

FIG. B1. The composite $Q$ profile at $t=0$ of the composite time series for WIG waves identified with the h25/15 filter. The values of $Q$ is calculated from JRA-25 (blue), NCEP (green), and ERAInterim (black) reanalysis and TRMM (red). 
ERA-Interim, NCEP-NCAR (Kalnay et al. 1996), and JRA-25 (Onogi et al. 2007) reanalysis data with TRMM latent heat product (Shige et al. 2004). Figure B1 shows $Q$ profile at composite center. A maximum of TRMM $Q$ profile is at $450 \mathrm{hPa}$, which matches best with ERAInterim: a maximum of $Q$ profile is between 400 and $500 \mathrm{hPa}$ for ERA-Interim, while it is at $300 \mathrm{hPa}$ for JRA-25 and NCEP. ERA-Interim is considered to be more appropriate for a study of 2-day waves than other reanalysis data.

\section{REFERENCES}

Back, L. E., and C. S. Bretherton, 2006: Geographic variability in the export of moist static energy and vertical motion profiles in the tropical Pacific. Geophys. Res. Lett., 33, L17810, https:// doi.org/10.1029/2006GL026672.

Blanco, J. E., D. S. Nolan, and B. E. Mapes, 2016: Convectively coupled Kelvin waves in aquachannel simulations: 2. Life cycle and dynamical-convective coupling. J. Geophys. Res. Atmos., 121, 11319-11347, https://doi.org/10.1002/2016JD025022.

Chen, S. S., and R. A. Houze Jr., 1997: Diurnal variation and lifecycle of deep convective systems over the tropical Pacific warm pool. Quart. J. Roy. Meteor. Soc., 123, 357-388, https:// doi.org/10.1002/qj.49712353806.

Clayson, C. A., B. Strahl, and J. Schrage, 2002: 2-3-day convective variability in the tropical western Pacific. Mon. Wea. Rev., 130, 529-548, https://doi.org/10.1175/1520-0493(2002)130<0529: DCVITT $>2.0 . \mathrm{CO} ; 2$.

Dias, J., and O. Pauluis, 2009: Convectively coupled waves propagating along an equatorial ITCZ. J. Atmos. Sci., 66, 22372255, https://doi.org/10.1175/2009JAS3020.1.

—_, and ——, 2011: Modulations of the phase speed of convectively coupled Kelvin waves by the ITCZ. J. Atmos. Sci., 68, 1446-1459, https://doi.org/10.1175/2011JAS3630.1.

_- and G. N. Kiladis, 2014: Influence of the basic state zonal flow on convectively coupled equatorial waves. Geophys. Res. Lett., 41, 6904-6913, https://doi.org/10.1002/2014GL061476.

—_, S. N. Tulich, and G. N. Kiladis, 2012: An object-based approach to assessing the organization of tropical convection. J. Atmos. Sci., 69, 2488-2504, https://doi.org/10.1175/ JAS-D-11-0293.1.

Emanuel, K. A., J. D. Neelin, and C. S. Bretherton, 1994: On largescale circulations in convecting atmospheres. Quart. J. Roy. Meteor. Soc., 120, 1111-1143, https://doi.org/10.1002/qj.49712051902.

Frierson, D. M., 2007: Convectively coupled Kelvin waves in an idealized moist general circulation model. J. Atmos. Sci., 64, 2076-2090, https://doi.org/10.1175/JAS3945.1.

_ A. J. Majda, and O. M. Pauluis, 2004: Large scale dynamics of precipitation fronts in the tropical atmosphere: A novel relaxation limit. Commun. Math. Sci., 2, 591-626, https://doi.org/ 10.4310/CMS.2004.v2.n4.a3.

Fuchs, Ž., and D. J. Raymond, 2007: A simple, vertically resolved model of tropical disturbances with a humidity closure. Tellus, 59, 344-354, https://doi.org/10.1111/j.1600-0870.2007.00230.x.

Fulton, S. R., and W. H. Schubert, 1985: Vertical normal mode transforms: Theory and application. Mon. Wea. Rev., 113, 647-658, https://doi.org/10.1175/1520-0493(1985)113<0647: VNMTTA $>2.0 . \mathrm{CO} ; 2$.

Haertel, P. T., and R. H. Johnson, 1998: Two-day disturbances in the equatorial western Pacific. Quart. J. Roy. Meteor. Soc., 124, 615-636, https://doi.org/10.1002/qj.49712454611.
-_, and G. N. Kiladis, 2004: Dynamics of 2-day equatorial waves. J. Atmos. Sci., 61, 2707-2721, https://doi.org/10.1175/ JAS3352.1.

,,-- A. Denno, and T. M. Rickenbach, 2008: Vertical-mode decompositions of 2-day waves and the Madden-Julian oscillation. J. Atmos. Sci., 65, 813-833, https://doi.org/10.1175/ 2007JAS2314.1.

_- K. K. Straub, and A. Budsock, 2015: Transforming circumnavigating Kelvin waves that initiate and dissipate the Madden-Julian oscillation. Quart. J. Roy. Meteor. Soc., 141, 1586-1602, https://doi.org/10.1002/qj.2461.

Iguchi, T., T. Kozu, R. Meneghini, J. Awaka, and K. Okamoto, 2000: Rain-profiling algorithm for the TRMM Precipitation Radar. J. Appl. Meteor., 39, 2038-2052, https://doi.org/10.1175/ 1520-0450(2001)040<2038:RPAFTT>2.0.CO;2.

Inoue, K., and L. Back, 2015: Column-integrated moist static energy budget analysis on various time scales during TOGA COARE. J. Atmos. Sci., 72, 1856-1871, https://doi.org/10.1175/ JAS-D-14-0249.1.

Janowiak, J. E., R. J. Joyce, and Y. Yarosh, 2001: A real-time global half-hourly pixel-resolution infrared dataset and its applications. Bull. Amer. Meteor. Soc., 82, 205-217, https://doi.org/10.1175/1520-0477(2001)082<0205:ARTGHH> 2.3.CO;2.

Kalnay, E., and Coauthors, 1996: The NCEP/NCAR 40-Year Reanalysis Project. Bull. Amer. Meteor. Soc., 77, 437-471, https://doi.org/10.1175/1520-0477(1996)077<0437:TNYRP> 2.0.CO;2.

Kasahara, A., and K. Puri, 1981: Spectral representation of threedimensional global data by expansion in normal mode functions. Mon. Wea. Rev., 109, 37-51, https://doi.org/10.1175/ 1520-0493(1981)109<0037:SROTDG >2.0.CO;2.

Khouider, B., and A. J. Majda, 2006a: A simple multicloud parameterization for convectively coupled tropical waves. Part I: Linear analysis. J. Atmos. Sci., 63, 1308-1323, https://doi.org/ 10.1175/JAS3677.1.

$\longrightarrow$, and — 2006b: Multicloud convective parametrizations with crude vertical structure. Theor. Comput. Fluid Dyn., 20, 351-375, https://doi.org/10.1007/s00162-006-0013-2.

Kiladis, G. N., M. C. Wheeler, P. T. Haertel, K. H. Straub, and P. E. Roundy, 2009: Convectively coupled equatorial waves. Rev. Geophys., 47, RG2003, https://doi.org/10.1029/ 2008RG000266.

Kim, J.-E., and M. J. Alexander, 2013: Tropical precipitation variability and convectively coupled equatorial waves on submonthly time scales in reanalyses and TRMM. J. Climate, $\mathbf{2 6}$, 3013-3030, https://doi.org/10.1175/JCLI-D-12-00353.1.

Kuang, Z., 2008a: Modeling the interaction between cumulus convection and linear gravity waves using a limited-domain cloud system-resolving model. J. Atmos. Sci., 65, 576-591, https://doi.org/10.1175/2007JAS2399.1.

__, 2008b: A moisture-stratiform instability for convectively coupled waves. J. Atmos. Sci., 65, 834-854, https://doi.org/ 10.1175/2007JAS2444.1.

Lindzen, R. S., 1967: Planetary waves on beta-planes. Mon. Wea. Rev., 95, 441-451, https://doi.org/10.1175/1520-0493(1967) 095<0441:PWOBP $>2.3$. CO;2.

Majda, A. J., and M. G. Shefter, 2001: Models for stratiform instability and convectively coupled waves. J. Atmos. Sci., 58, 1567-1584, https://doi.org/10.1175/1520-0469(2001)058<1567: MFSIAC $>2.0 . \mathrm{CO} ; 2$.

, B. Khouider, G. N. Kiladis, K. H. Straub, and M. G. Shefter, 2004: A model for convectively coupled tropical waves: 
Nonlinearity, rotation, and comparison with observations. J. Atmos. Sci., 61, 2188-2205, https://doi.org/10.1175/15200469(2004)061<2188:AMFCCT>2.0.CO;2.

Mapes, B. E., 1998: The large-scale part of tropical mesoscale convective system circulations: A linear vertical spectral band model. J. Meteor. Soc. Japan, 76, 29-55, https://doi.org/ 10.2151/jmsj1965.76.1_29.

, 2000: Convective inhibition, subgrid-scale triggering energy, and stratiform instability in a toy tropical wave model. J. Atmos. Sci., 57, 1515-1535, https://doi.org/10.1175/15200469(2000)057<1515:CISSTE > 2.0.CO;2.

— western Pacific mesoscale convective systems. J. Atmos. Sci., 52, 1807-1828, https://doi.org/10.1175/1520-0469(1995)052<1807: DDPIWP $>2.0 . \mathrm{CO} ; 2$.

Masunaga, H., T. S. L'Ecuyer, and C. D. Kummerow, 2006: The Madden-Julian oscillation recorded in early observations from the Tropical Rainfall Measuring Mission (TRMM). J. Atmos. Sci., 63, 2777-2794, https://doi.org/10.1175/JAS3783.1.

Matsuno, T., 1966: Quasi-geostrophic motions in the equatorial area. J. Meteor. Soc. Japan, 44, 25-43, https://doi.org/10.2151/ jmsj1965.44.1_25.

Nakazawa, T., 1988: Tropical super clusters within intraseasonal variations over the western Pacific. J. Meteor. Soc. Japan, 66 , 823-839, https://doi.org/10.2151/jmsj1965.66.6_823.

Neelin, J. D., and I. M. Held, 1987: Modeling tropical convergence based on the moist static energy budget. Mon. Wea. Rev. 115, 3-12, https://doi.org/10.1175/1520-0493(1987)115<0003: MTCBOT>2.0.CO;2.

__ , and J.-Y. Yu, 1994: Modes of tropical variability under convective adjustment and the Madden-Julian oscillation. Part I: Analytical theory. J. Atmos. Sci., 51, 1876-1894, https://doi.org/10.1175/1520-0469(1994)051<1876:MOTVUC> 2.0.CO;2.

Onogi, K., and Coauthors, 2007: The JRA-25 Reanalysis. J. Meteor. Soc. Japan, 85, 369-432, https://doi.org/10.2151/jmsj.85.369.

Peters, M. E., and C. S. Bretherton, 2006: Structure of tropical variability from a vertical mode perspective. Theor. Comput. Fluid Dyn., 20, 501-524, https://doi.org/10.1007/s00162-0060034-x.

Powell, S. W., 2017: Successive MJO propagation in MERRA-2 reanalysis. Geophys. Res. Lett., 44, 5178-5186, https://doi.org/ 10.1002/2017GL073399.

Raymond, D. J., 2001: A new model of the Madden-Julian oscillation. J. Atmos. Sci., 58, 2807-2819, https://doi.org/10.1175/ 1520-0469(2001)058<2807:ANMOTM>2.0.CO;2.

— ture modes in a simple atmospheric model. Tellus, 59A, 627640, https://doi.org/10.1111/j.1600-0870.2007.00268.x.

—_ S. L. Sessions, A. H. Sobel, and Ž. Fuchs, 2009: The mechanics of gross moist stability. J. Adv. Model. Earth Syst., 1 (3), https://doi.org/10.3894/JAMES.2009.1.9.

Roundy, P. E., 2008: Analysis of convectively coupled Kelvin waves in the Indian Ocean MJO. J. Atmos. Sci., 65, 1342-1359, https://doi.org/10.1175/2007JAS2345.1.

—_, and W. M. Frank, 2004: A climatology of waves in the equatorial region. J. Atmos. Sci., 61, 2105-2132, https://doi.org/ 10.1175/1520-0469(2004)061<2105:ACOWIT>2.0.CO;2.

Shige, S., Y. N. Takayabu, W.-K. Tao, and D. E. Johnson, 2004: Spectral retrieval of latent heating profiles from TRMM PR data. Part I: Development of a model-based algorithm. J. Appl. Meteor., 43, 1095-1113, https://doi.org/10.1175/15200450(2004)043<1095:SROLHP>2.0.CO;2.
Silva Dias, P. L., W. H. Schubert, and M. DeMaria, 1983: Largescale response of the tropical atmosphere to transient convection. J. Atmos. Sci., 40, 2689-2707, https://doi.org/10.1175/ 1520-0469(1983)040<2689:LSROTT>2.0.CO;2.

Simmons, A., S. Uppala, D. Dee, and S. Kobayashi, 2007: ERAInterim: New ECMWF reanalysis products from 1989 onwards. ECMWF Newsletter, No. 110, ECMWF, Reading, United Kingdom, 25-35.

Sobel, A. H., and C. S. Bretherton, 2003: Large-scale waves interacting with deep convection in idealized mesoscale model simulations. Tellus, 55A, 45-60, https://doi.org/10.3402/tellusa.v55i1.12084.

Stechmann, S. N., and A. J. Majda, 2009: Gravity waves in shear and implications for organized convection. J. Atmos. Sci., 66, 2579-2599, https://doi.org/10.1175/2009JAS2976.1.

Straub, K. H., and G. N. Kiladis, 2002: Observations of a convectively coupled Kelvin wave in the eastern Pacific ITCZ. J. Atmos. Sci., 59, 30-53, https://doi.org/10.1175/1520-0469(2002) 059<0030:OOACCK >2.0.CO;2.

— pled Kelvin waves: Comparison with simple models of coupled wave instability. J. Atmos. Sci., 60, 1655-1668, https://doi.org/ 10.1175/1520-0469(2003)060<1655:TOSOCC $>2.0$.CO;2.

Sumi, Y., and H. Masunaga, 2016: A moist static energy budget analysis of quasi-2-day waves using satellite and reanalysis data. J. Atmos. Sci. 73, 743-759, https://doi.org/10.1175/JAS-D-15-0098.1.

Takayabu, Y. N., 1994a: Large-scale cloud disturbances associated with equatorial waves. Part I: Spectral features of the cloud disturbances. J. Meteor. Soc. Japan, 72, 433-449, https:// doi.org/10.2151/jmsj1965.72.3_433.

_ equatorial waves. Part II: Westward-propagating inertiogravity waves. J. Meteor. Soc. Japan, 72, 451-465, https:// doi.org/10.2151/jmsj1965.72.3_451.

—, K.-M. Lau, and C.-H. Sui, 1996: Observation of a quasi-2-day wave during TOGA COARE. Mon. Wea. Rev., 124, 18921913, https://doi.org/10.1175/1520-0493(1996)124<1892: OOAQDW $>2.0 . \mathrm{CO} ; 2$.

Tian, B., and V. Ramanathan, 2003: A simple moist tropical atmosphere model: The role of cloud radiative forcing. J. Climate, 16, 2086-2092, https://doi.org/10.1175/15200442(2003)016<2086:ASMTAM >2.0.CO;2.

Tulich, S. N., and B. E. Mapes, 2008: Multiscale convective wave disturbances in the tropics: Insights from a two-dimensional cloud-resolving model. J. Atmos. Sci., 65, 140-155, https:// doi.org/10.1175/2007JAS2353.1.

$\longrightarrow$, and - 2010: Transient environmental sensitivities of explicitly simulated tropical convection. J. Atmos. Sci., 67, 923940, https://doi.org/10.1175/2009JAS3277.1.

_ , and G. N. Kiladis, 2012: Squall lines and convectively coupled gravity waves in the tropics: Why do most cloud systems propagate westward? J. Atmos. Sci., 69, 2995-3012, https:// doi.org/10.1175/JAS-D-11-0297.1.

D. A. Randall, and B. E. Mapes, 2007: Vertical-mode and cloud decomposition of large-scale convectively coupled gravity waves in a two-dimensional cloud-resolving model. J. Atmos. Sci., 64, 1210-1229, https://doi.org/10.1175/JAS3884.1.

Wheeler, M., and G. N. Kiladis, 1999: Convectively coupled equatorial waves: Analysis of clouds and temperature in the wavenumber-frequency domain. J. Atmos. Sci., 56, 374-399, https://doi.org/10.1175/1520-0469(1999)056<0374:CCEWAO> 2.0.CO;2.

- —_, and P. J. Webster, 2000: Large-scale dynamical fields associated with convectively coupled equatorial waves. 
J. Atmos. Sci., 57, 613-640, https://doi.org/10.1175/15200469(2000)057<0613:LSDFAW>2.0.CO;2.

Yanai, M., S. Esbensen, and J.-H. Chu, 1973: Determination of bulk properties of tropical cloud clusters from large-scale heat and moisture budgets. J. Atmos. Sci., 30, 611-627, https://doi.org/ 10.1175/1520-0469(1973)030<0611:DOBPOT>2.0.CO;2.

Yang, G.-Y., B. Hoskins, and J. Slingo, 2003: Convectively coupled equatorial waves: A new methodology for identifying wave structures in observational data. J. Atmos. Sci., 60, 1637-1654, https:// doi.org/10.1175/1520-0469(2003)060<1637:CCEWAN>2.0.CO;2.

, — , and —, 2007a: Convectively coupled equatorial waves. Part I: Horizontal and vertical structures. J. Atmos. Sci., 64, 3406-3423, https://doi.org/10.1175/JAS4017.1.

, and $-2007 \mathrm{~b}$ : Convectively coupled equatorial waves. Part II: Propagation characteristics. J. Atmos. Sci., 64, 3424-3437, https://doi.org/10.1175/JAS4018.1.
Yano, J.-I., and K. Emanuel, 1991: An improved model of the equatorial troposphere and its coupling with the stratosphere. J. Atmos. Sci., 48, 377-389, https://doi.org/10.1175/15200469(1991)048<0377:AIMOTE > 2.0.CO;2.

Yasunaga, K., and B. Mapes, 2012: Differences between more divergent and more rotational types of convectively coupled equatorial waves. Part I: Space-time spectral analyses. J. Atmos. Sci., 69, 3-16, https://doi.org/10.1175/JAS-D11-033.1.

— components of convectively coupled equatorial waves. J. Atmos. Sci., 71, 98-111, https://doi.org/10.1175/JAS-D-13-03.1.

Zhang, C., and P. J. Webster, 1989: Effects of zonal flows on equatorially trapped waves. J. Atmos. Sci., 46, 3632-3652, https://doi.org/10.1175/1520-0469(1989)046<3632:EOZFOE> 2.0.CO;2. 